\title{
FxLMS Method for Suppressing In-Wheel Switched Reluctance Motor Vertical Force Based on Vehicle Active Suspension System
}

\author{
Yan-yang Wang, Yi-nong Li, Wei Sun, Chao Yang, and Guang-hui Xu \\ The State Key Laboratory of Mechanical Transmission, Chongqing University, Chongqing 400044, China \\ Correspondence should be addressed to Yi-nong Li; ynli@cqu.edu.cn
}

Received 27 January 2014; Revised 27 April 2014; Accepted 16 May 2014; Published 4 June 2014

Academic Editor: Yang Shi

Copyright ( 2014 Yan-yang Wang et al. This is an open access article distributed under the Creative Commons Attribution License, which permits unrestricted use, distribution, and reproduction in any medium, provided the original work is properly cited.

\begin{abstract}
The vibration of SRM obtains less attention for in-wheel motor applications according to the present research works. In this paper, the vertical component of SRM unbalanced radial force, which is named as SRM vertical force, is taken into account in suspension performance for in-wheel motor driven electric vehicles (IWM-EV). The analysis results suggest that SRM vertical force has a great effect on suspension performance. The direct cause for this phenomenon is that SRM vertical force is directly exerted on the wheel, which will result in great variation in tyre dynamic load and the tyre will easily jump off the ground. Furthermore, the frequency of SRM vertical force is broad which covers the suspension resonance frequencies. So it is easy to arouse suspension resonance and greatly damage suspension performance. Aiming at the new problem, FxLMS (filtered-X least mean square) controller is proposed to improve suspension performance. The FxLMS controller is based on active suspension system which can generate the controllable force to suppress the vibration caused by SRM vertical force. The conclusion shows that it is effective to take advantage of active suspensions to reduce the effect of SRM vertical force on suspension performance.
\end{abstract}

\section{Introduction}

Electric vehicles have achieved sufficient driving performance due to the great improvements in motors and batteries. Due to the remarkable advantages, for example, highly efficient transfer of power, driving force to be distributed freely, and space saving and packaging, the in-wheel motor technology has become the focus of electric vehicle investigation [1-3]. As the key component of propulsion system, electric motors play an important role in in-wheel motor driven electric vehicles (IWM-EV) dynamics. It is desired that electric motors of electric vehicles have a wide operating speed range, high torque density, a high starting torque for initial acceleration, and high efficiency to extend the battery serve-life $[4,5]$. And the switched reluctance motor (SRM) exactly satisfied the above requirements [6-8]. However, these advantages of SRM are overshadowed by its inherent high torque ripple and vibration, which seriously hindered the development of SRM for in-wheel motor applications [912]. To reduce or eliminate the insufficiency of SRM, much attention has been focused on SRM structure and control.
To improve the performance of SRM, the common solution is to increase SRM power density starting torque and efficiency by optimal control method or multiobjective systematic optimization design [13-16]. These existing researches mainly focus on the SRM's power or torque characteristics, which leave other factors, such as torque ripple, the vibration, and noise, out of consideration. However, torque ripple and the vibration will greatly limit the performance of SRM and further reduce the stability and comfort of electric vehicle [9-11].

To suppress SRM vibration, some structures and controllers are investigated. Inagaki et al. [17] proposed a twodegree-of-freedom $H_{\infty}$ control to suppress vehicle drive train vibration which was caused by SRM torque ripple and radial force. By controlling the current waveform, the radial force of SRM is reduced. Marques dos Santos et al. $[10,18]$ presented a multiphysics analysis to predict acoustic radiation properties of SRM for an electric vehicle. Li and Cho [19] proposed a method to reduce the unbalanced radial force and vibration of SRM by introducing parallel paths in windings. These results revealed that the currents could be balanced in parallel 
paths and unbalanced radial force could be reduced. These existing researches contribute to suppress SRM vibration; however, the SRM vibration effect on vehicle stability and comfort is seldom considered. The role and effect of IWMEV suspension performance need to be considered further.

Unbalanced radial force caused by rotor eccentricity may degrade the performance of SRM, increasing vibration and acoustic noise $[12,19-23]$. In practice, some degree of rotor eccentricity is always present due to the tolerances introduced during the manufacturing process, wear of bearings, and static friction especially when the rotor is sitting idle, as well as other reasons $[9,12,24]$. The air gap of the SRM is generally between 0.2 and $1 \mathrm{~mm}$ which is much smaller than any other type of motor and is more sensitive to rotor eccentricity. A relative eccentricity between the stator and rotor of $10 \%$ is common $[24,25]$. On the other hand, SRM unbalanced radial force will be magnified by the vehicle continuously idling, road excitation, and unbalanced load. This phenomenon is particularly serious to IWM-EV, because the vertical component of SRM unbalanced radial force, namely, SRM vertical force, applies directly on vehicle wheels and will change the tyre load. Although SRM unbalanced radial force is inevitable and serious, the contributions of SRM unbalanced radial force to IWM-EV stability and comfort have not been studied thoroughly yet.

After a review of the past studies on in-wheel motor and SRM, it is found that one key problem needs to be considered; for example, the effect of SRM vertical force on vehicle suspension performance needs to be discovered; a reasonable method to solve this new problem needs to be developed, and such work is consequently investigated in this research.

This paper is organized as follows: first of all, the quartercar suspension model of a IWM-EV is given, followed by the development of SRM model and vertical force model. Then the effect of SRM vertical force on suspension performance is investigated under wheel resonance in Section 3. To reduce the effect of SRM vertical force and improve suspension performance, the FxLMS (filtered-X least mean square) controller is developed based on active suspension in Section 4. Computer simulations and discussions of the results are provided in Section 5. And finally, the conclusions drawn from this research are presented.

\section{Vehicle Modeling}

The vehicle model consists of three submodels: the suspension model that emphasizes the effect of SRM vertical force, which is a new vertical excitement of vehicle suspension; the SRM model that provides the desired torque for vehicle; SRM vertical force model, which works out the vertical force that SRM exerts on wheel.

2.1. Suspension Model. A two-degree-of-freedom (2DOF) vehicle suspension system is used as shown in Figure 1. This suspension model is widely used to study the conflicting dynamic performances of a vehicle suspension such as ride quality and road holding [26-29]. The vehicle suspension

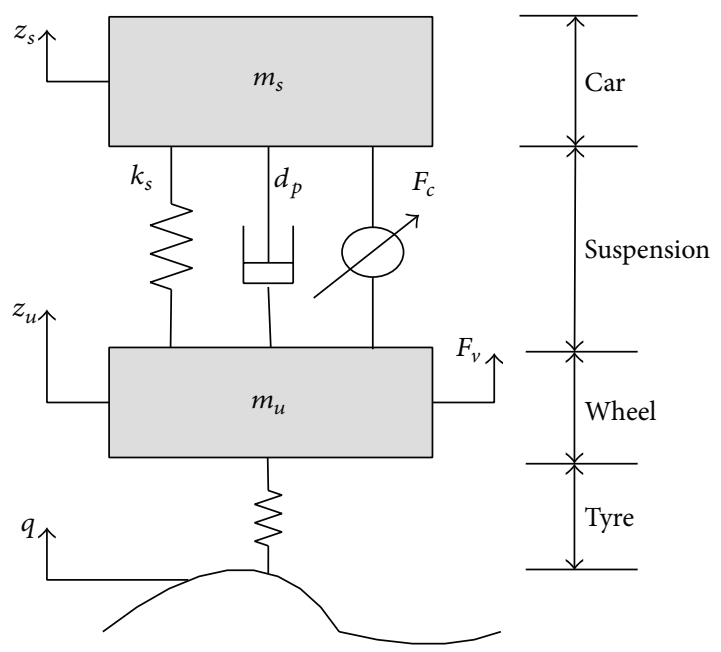

Figure 1: Quarter-car suspension.

system mainly includes three components: sprung mass, suspension actuator, and unsprung mass, which is shown in Figure 1 of the paper. The sprung mass represents the vehicle body, of which the vibration will reduce vehicle comfort performance. The unsprung mass represents the wheel and tyre. The vibration of unsprung mass is related to vehicle stability. Due to the road and external excitation being time-varying, the desired force which is used to suppress vehicle vibration is expected to be adjustable. So the active suspension actuator is used to suppress the vibration, which can generate the controllable force. SRM is a new type of in-wheel motor, which is mounted in wheel as a part of vehicle unsprung mass. SRM vertical force is directly exerted on the wheel. What is important in this study is that SRM vertical force is brought into the in-wheel motored vehicle suspension. The governing equations of suspension dynamics can be described as

$$
\begin{aligned}
& m_{s} \ddot{z}_{s}=-d_{p}\left(\dot{z}_{s}-\dot{z}_{u}\right)-k_{s}\left(z_{s}-z_{u}\right)-F_{c} \\
& m_{u} \ddot{z}_{u}=d_{p}\left(\dot{z}_{s}-\dot{z}_{u}\right)+k_{s}\left(z_{s}-z_{u}\right)-k_{t}\left(z_{u}-q\right)+F_{c}+F_{v},
\end{aligned}
$$

where $m_{s}$ is the sprung mass, which represents the vehicle body; $m_{u}$ is the unsprung mass, which represents the wheel assembly; $z_{s}$ and $z_{u}$ are the displacement of sprung and unsprung mass, respectively, and $k_{t}$ serves to model the compressibility of the pneumatic tyre; $q$ is the road displacement input; $F_{v}$ is the vertical force generated by SRM; $F_{c}$ means the controllable force of active suspension; $d_{p}$ and $k_{s}$ are damping and stiffness of the passive suspension system, respectively. Note that if the controllable force $F_{c}=0$ and without considering SRM vertical force, then the active suspension system becomes a passive suspension system. And the parameters of the suspension of IWM-EV are listed in Table 3.

The tyre dynamic load is

$$
S_{z}=k_{t}\left(z_{u}-q\right) \text {. }
$$




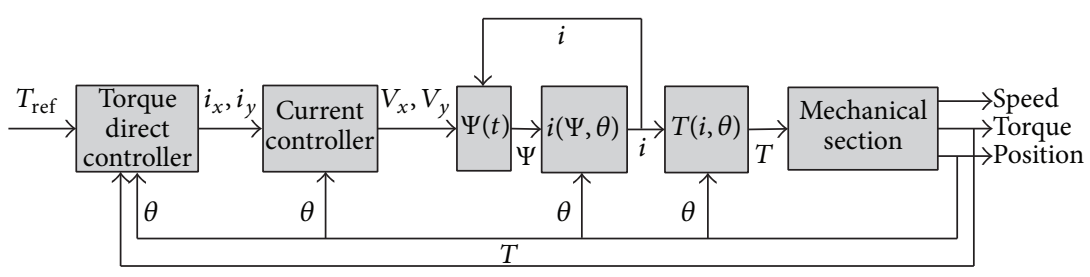

FIGURE 2: SRM model configuration.

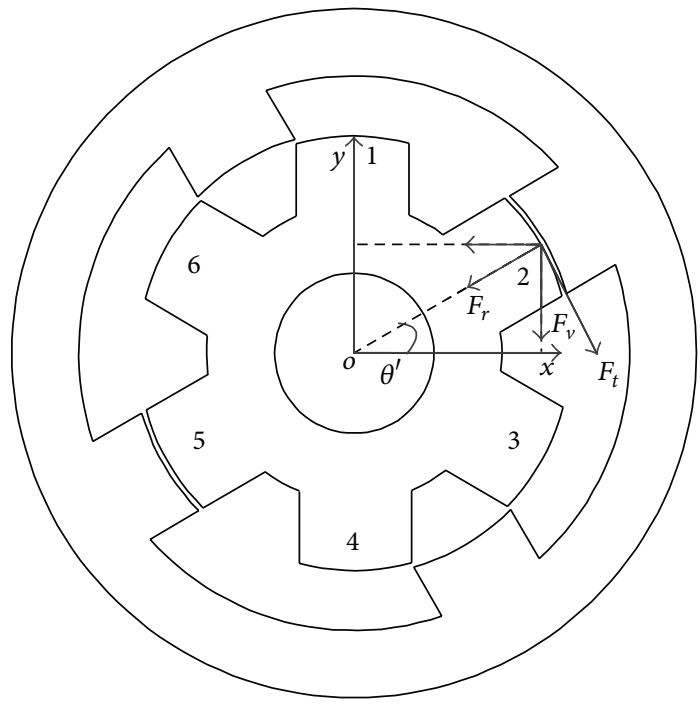

(a) The eccentric rotor overlap stators 2 and 5

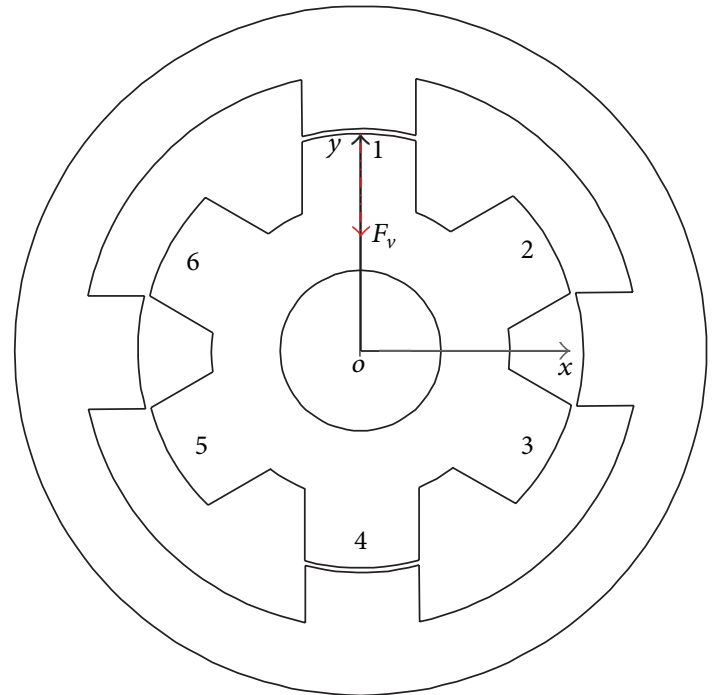

(b) The eccentric rotor overlap stators 1 and 4

FIGURE 3: SRM vertical force.

For the passive suspension system, the sprung and unsprung natural frequency is

$$
\begin{aligned}
& \omega_{1}=\frac{1}{2 \pi} \sqrt{\frac{k_{s}}{m_{s}}} \\
& \omega_{2}=\frac{1}{2 \pi} \sqrt{\frac{k_{t}+k_{s}}{m_{u}} .}
\end{aligned}
$$

According to (3), the sprung and unsprung natural frequency of passive suspension system are $1.3 \mathrm{~Hz}$ and $7.5 \mathrm{~Hz}$, respectively. And it is easy to cause suspension resonance when the frequency of excitation, for example, SRM vertical force, is near the natural frequency.

2.2. SRM Model. The SRM model is used to generate the drive torque for vehicle. The magnetization characteristic, torque characteristic, mechanical section of the plant, and direct torque control of SRM are shown in Figure 2. The look-up table method is used to simulate the characteristic of SRM and design SRM controller. The table values of $i(\psi, \theta)$ and $T(i, \theta)$ are obtained by analytical formulations, which are easy to implement and convenient by discrete method [30-32]. The reference torque $T_{\text {ref }}$ is determined by in-wheel motor operation states. According to torque direct controller, the control current of conducting-phase $i_{x}, i_{y}$ is determined which can be translated to control voltage $V_{x}, V_{y}$ by current controller [33]. Control voltage $V_{x}, V_{y}$ is used to generate the flux of SRM. Looking-up table, $i(\psi, \theta)$ and $T(i, \theta)$ can get motor torque. The torques produced by all stator phases are then summed up to provide the total torque on the rotor shaft.

In the electrical circuit of SRM, the magnetic flux linkage in the windings is obtained as follows:

$$
\psi(t)=\int_{0}^{t}(V-R i) d t
$$

where $V$ is the stator voltage vector; $R$ is the stator winding resistance. This equation is used to calculate SRM flux values which are supplied to table $i(\psi, \theta)$ as shown in Figure 2.

According to SRM analytical model, the inductance $L$ and magnetization characteristic $\psi$ of SRM can be expressed as a function of stator current and rotor position:

$$
\begin{aligned}
& L(i, \theta)=L_{q}+\left[L_{d s \mathrm{at}}+\frac{A\left(1-e^{-B i}\right)}{i}-L_{q}\right] f(\theta), \\
& \psi(i, \theta)=L(i, \theta) i,
\end{aligned}
$$

where $A=\Psi_{m}-L_{\text {sat }} I_{m}, B=\left(L_{d}-L_{d \text { sat }}\right) / A, f(\theta)=(2 *$ $\left.N_{r}^{3} / \pi^{3}\right) \theta^{3}-\left(3 * N_{r}^{2} / \pi^{2}\right) \theta^{2}+1, L_{q}$ is minimum inductance, $L_{d}$ is the maximum inductance, $L_{d s a t}$ is the saturated inductance, $\psi_{m}$ is the maximum flux linkage, $I_{m}$ is the maximum current, 


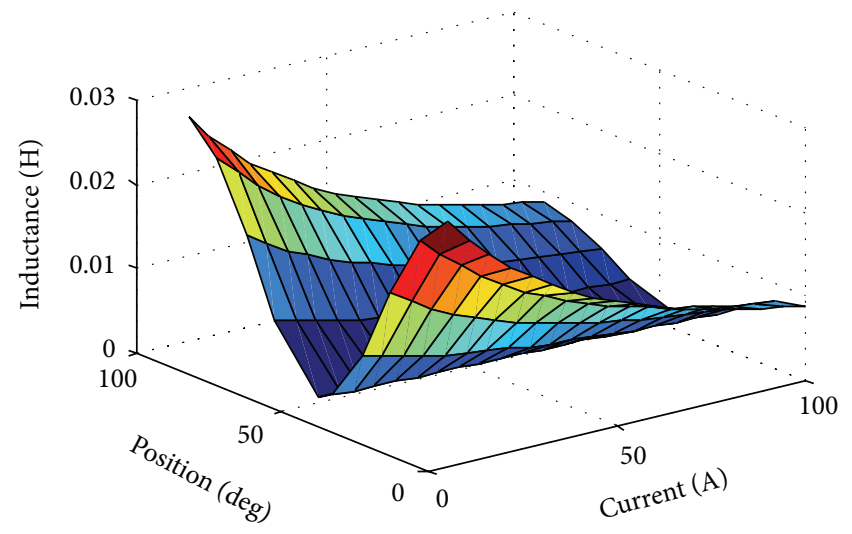

(a) Inductance characteristic

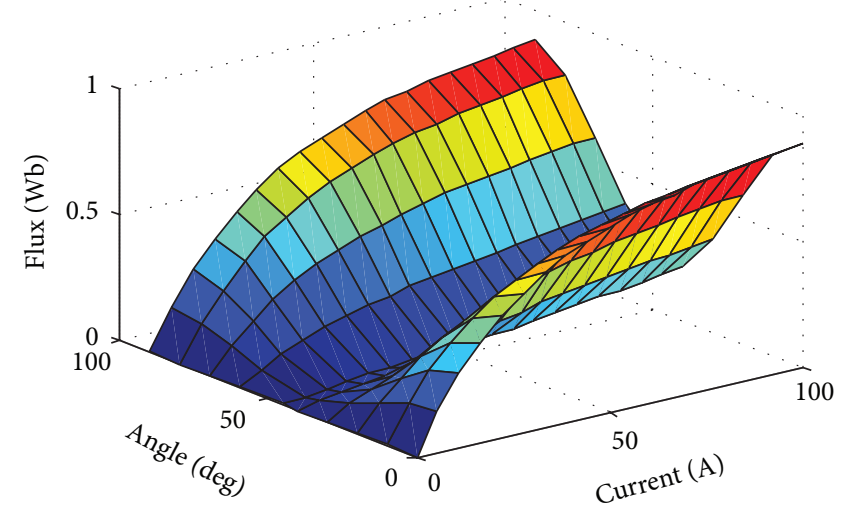

(b) Flux characteristic

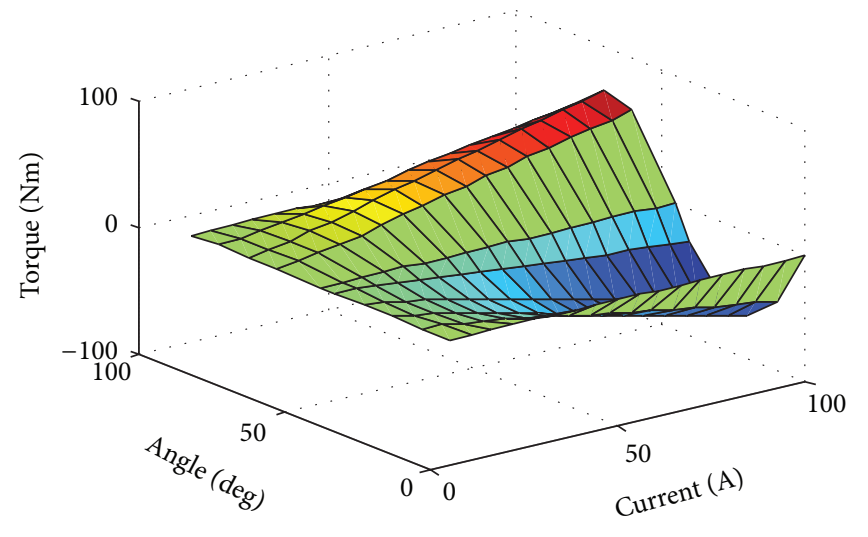

(c) Torque characteristic

FIGURE 4: Characteristics of SRM.

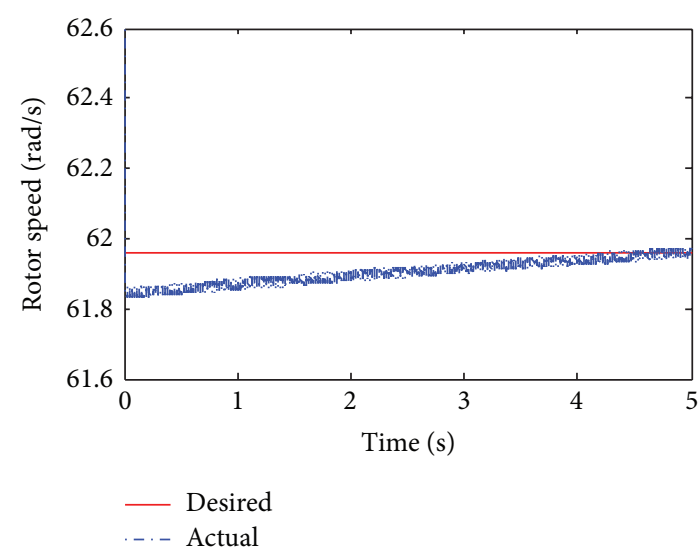

(a) Speed of SRM

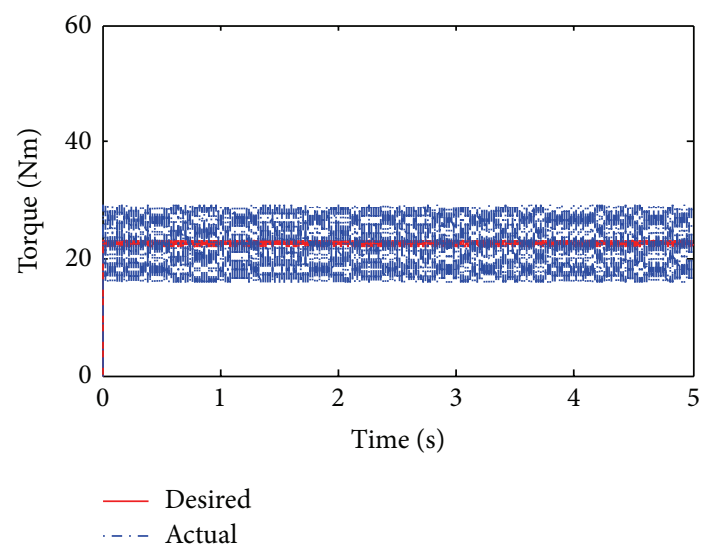

(b) Torque of SRM

FIGURE 5: Comparison of actual and desired value of SRM response at velocity $60 \mathrm{~km} / \mathrm{h}$.

$\theta$ is the rotor position, $i$ is the phase current, and $N_{r}$ is the number of rotor poles. The table value of $\psi(i, \theta)$ is calculated from the analytical equation (5) by discrete method. Using cubic spline interpolation, the table $i(\psi, \theta)$ is produced from the flux table $\psi(i, \theta)$.
The analytical expression for the torque can be described as

$$
T(i, \theta)=-\frac{i^{2}}{2} \frac{\partial L}{\partial \theta} .
$$




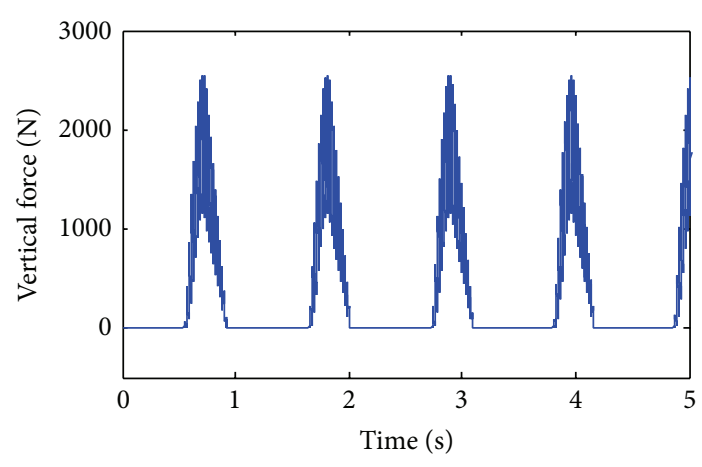

(a1)

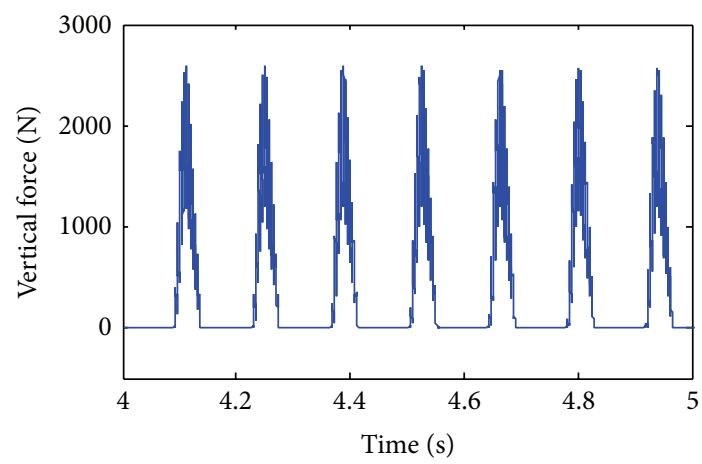

(b1)

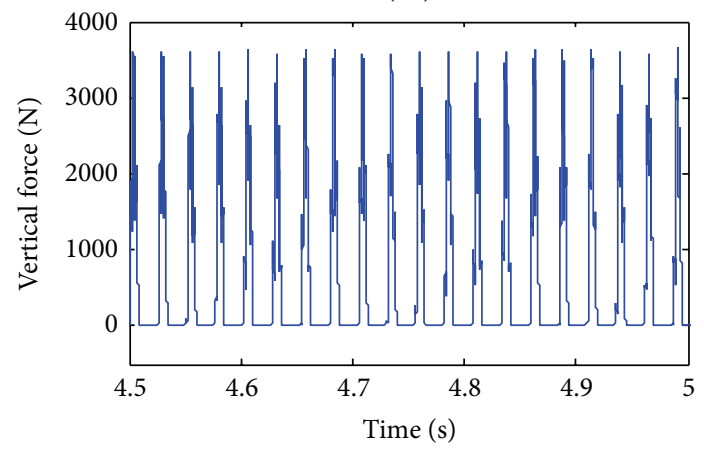

(c1)

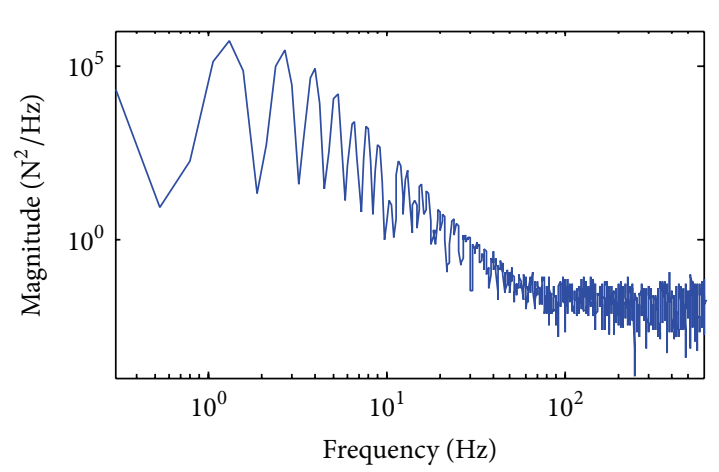

(a2)

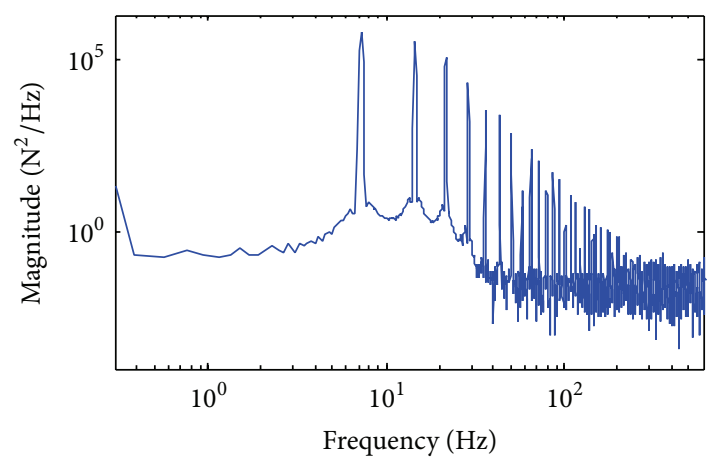

(b2)

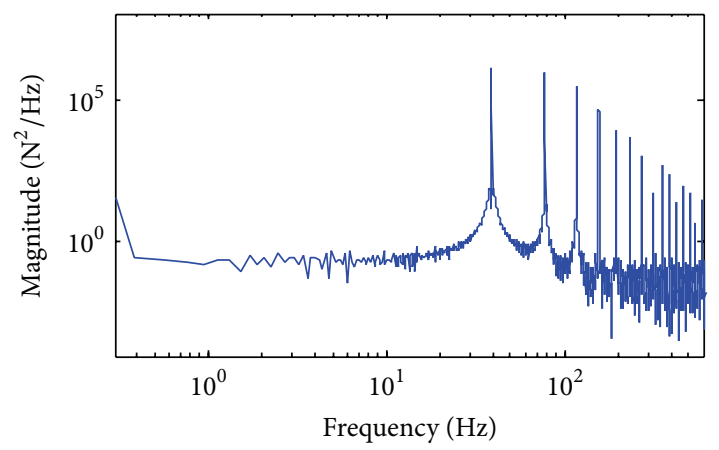

(c2)

FIGURE 6: SRM vertical force. (a1) Time history of vertical force at vehicle $2 \mathrm{~km} / \mathrm{h}$. (a2) PSD of vertical force at vehicle $2 \mathrm{~km} / \mathrm{h}$. (b1) Time history of vertical force at vehicle $11 \mathrm{~km} / \mathrm{h}$. (b2) PSD of vertical force at vehicle $11 \mathrm{~km} / \mathrm{h}$. (cl) Time history of vertical force at vehicle $60 \mathrm{~km} / \mathrm{h}$. (c2) PSD of vertical force at vehicle $60 \mathrm{~km} / \mathrm{h}$.

The table values of $T(i, \theta)$ are calculated from the analytical equation (6).

The mechanical dynamics of the motor and load are governed by the motion equation

$$
T=J \frac{d \Omega}{d t}+B \Omega+T_{L}
$$

where $\Omega$ is the rotor speed, $J$ is the moment of inertia, $B$ is the torque friction coefficient, and $T_{L}$ is the load toque which is determined by IWM-EV operation states.

The control method of SRM is a commonly used direct torque control method $[33,34]$. The main advantages of direct torque control are fast torque response and lower torque ripple, which meet the requirements of IWM-EV.
2.3. SRM Vertical Force Model. The primary purpose of SRM vertical force model is to work out SRM vertical force which is accompanied by the forming of torque. The electromagnetic force of SRM can be separated into a tangential and a radial force. The tangential force converts to the rotational torque which will drive IWM-EV. The radial force has no attribution to the rotation of SRM; however, it is the dominant noise source which could excite stator vibrations and emit acoustic noise. The net radial force is ideally zero because of the geometrical balance motor structure. However, due to the fabrication tolerances, the wheel motor often sits idle in vehicle common manoeuvre, unbalanced loads, and road excitations; the actual net radial force is usually not zero and results in the unbalanced radical force, as described in Section 1. What is important in this study is that the SRM 


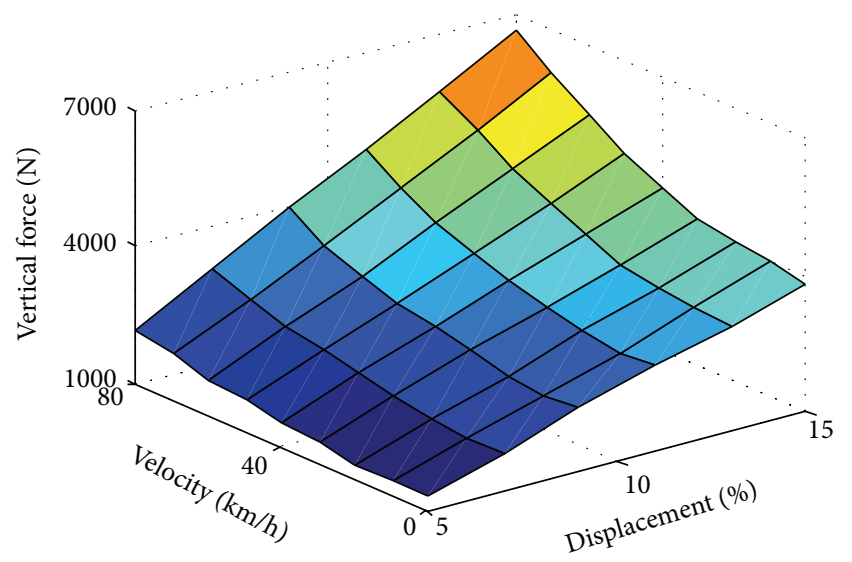

FIGURE 7: SRM vertical force (unit: N).

unbalanced radial force is taken into account as the wheel vertical excitation.

The unbalanced radial force is the radial force difference between a pair of opposite stator poles. Many methods can be used to calculate SRM radial force $[23,33,35]$. In this paper, the method of [33] is used. The benefit of this method is that only four parameters are needed. According to [33], the radial force of opposite stator poles can be described as follows:

$$
\begin{aligned}
& F_{1}=-\frac{r \sin \left(\theta_{o}\right)}{g_{m}-\Delta g} F_{t}, \\
& F_{2}=-\frac{r \sin \left(\theta_{o}\right)}{g_{m}+\Delta g} F_{t} .
\end{aligned}
$$

The unbalanced radical force is

$$
F_{r}=F_{1}-F_{2} \text {. }
$$

And SRM vertical force on the wheel is

$$
F_{v}=F_{r} \sin \left(\theta^{\prime}\right)
$$

where $r$ is the outer radius of the rotor, $g_{m}$ is air gap of SRM, and $\theta_{o}$ is stator and rotor pole overlap position which will be changed with rotor position $\theta$. For 6/4 SRM, the range of $\theta_{o}$ is $[0,30]$ degree [33]. $\theta^{\prime}$ is the angle between stator and wheel longitudinal axis. $F_{t}$ means the tangential force of SRM. It is obtained by dividing the tangential torque by the radius of the rotor pole. And $\Delta g$ means the rotor relative displacement, which will directly affect the unbalanced radical force value.

The 6/4 outside-rotor SRM is used in this study. The main advantage of the outside-rotor structure is the gearless operation, which will reduce the drive line components, thus improving the overall reliability and efficiency [36]. The similar structure is already validated in $[37,38]$. The air gap eccentricity includes two types, static eccentricity and dynamics eccentricity $[22,39,40]$. For the convenience of the presentation, we focus on the static type in our research. For static eccentricity, the relative eccentricity $\varepsilon$ is

$$
\varepsilon=\frac{x}{g} 100 \%
$$

where $g$ is the radial air gap length in the case of uniform air gap or no eccentricity and $x$ is the eccentricity in the horizontal (or vertical) direction. The eccentric positioning of the SRM creates unbalanced electromechanical radial forces due to asymmetrical magnetic pull as shown in Figure 3. For 6/4 outside-rotor SRM, the degree between adjacent stator is 60 degrees and adjacent rotor is 90 degrees. When the eccentric rotor overlap stators are 2 and 5 , the $\theta^{\prime}$ is 30 degrees. Similarly, when the eccentric rotor overlap stators are 1 and 4, the $\theta^{\prime}$ is 90 degrees as shown in Figure 3(b). So the longitudinal force component of SRM vertical force is zero under this condition. It means that the SRM unbalanced radial force is equal to SRM vertical force, and (10) is simplified to $F_{v}=F_{r}$. In the actual working condition, the unbalanced radial force is distributed along the stator radius. And each pair of opposite rotors with eccentricity can generate unbalanced radial force. For the convenience of presentation, we take a situation, where the eccentric rotor overlap stators are 1 and 4 , as an example to investigate SRM vertical force effect on vehicle dynamics. As the discussion above, the relative eccentricity between the stator and rotor of $10 \%$ is common. So in the following study, we mainly discuss the effect of SRM vertical force under $10 \%$ eccentricity conditions.

\section{Effect of SRM Vertical Force on Suspension Performance}

Resonance vibration of vehicle is very common and severe, so it is necessary to look at the effect of this kind of vibration induced by SRM vertical force. The extreme case is when SRM vertical force excitation frequency is inducing resonance of vehicle suspension; that is, the frequency is about sprung mass natural frequency of passive suspension system $1.3 \mathrm{~Hz}$ and wheel natural frequency $7.5 \mathrm{~Hz}$. The rotor pole number of SRM is 4, which means the vertical force frequency is four times of the wheel rotation frequency. So when the frequency of SRM vertical force is $1.3 \mathrm{~Hz}$ and $7.5 \mathrm{~Hz}$, the vehicle velocity is about $2 \mathrm{~km} / \mathrm{h}(1.3 \mathrm{~Hz} / 4 \times 2 \times \mathrm{pi} \times 0.269$ is $2 \mathrm{~km} / \mathrm{h})$ and $11 \mathrm{~km} / \mathrm{h}$ $(7.5 \mathrm{~Hz} / 4 \times 2 \times$ pi $\times 0.269$ is $11 \mathrm{~km} / \mathrm{h})$, respectively. Although the vehicle speed is too low for daily drive under the two severe cases, it is valuable to study it because the human body is sensitive to vertical vibration at low frequencies $(<10 \mathrm{~Hz})$. In another aspect, the vehicle is often sitting idle, stops, or starts up and the speed is very low under congested urban driving conditions. Next, we will look into the effect of suspension vibration induced by SRM vertical force.

3.1. Preliminary Analysis on SRM Vertical Force. In this section, the effect of SRM vertical force at vehicle speed $2 \mathrm{~km} / \mathrm{h}$, $11 \mathrm{~km} / \mathrm{h}$, and $60 \mathrm{~km} / \mathrm{h}$ is analysed. Computer simulations are performed to verify the effectiveness of SRM controller and analyse the vibration phenomenon. The specifications of the 6/4 outside-rotor SRM are listed in Table 4. From the look-up tables, the flux and torque characteristics of SRM are shown in Figure 4. And the response of the SRM speed and torque at vehicle speed $60 \mathrm{~km} / \mathrm{h}$ is shown in Figure 5 . It shows that the actual rotor speed and torque of the motor dynamics 


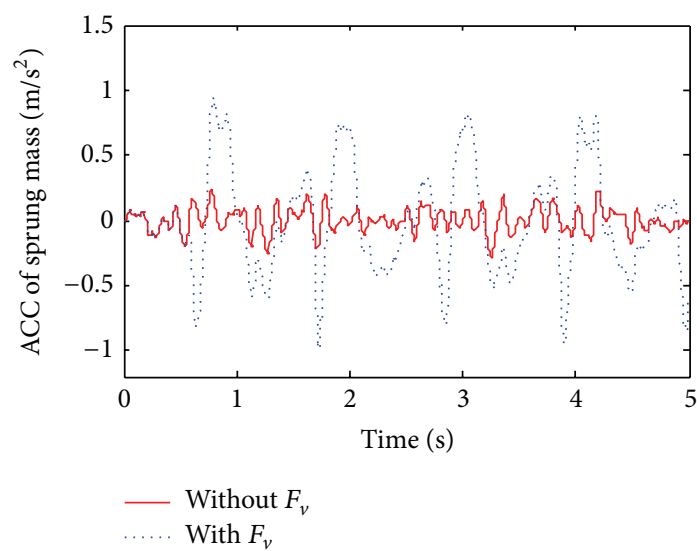

(a1)

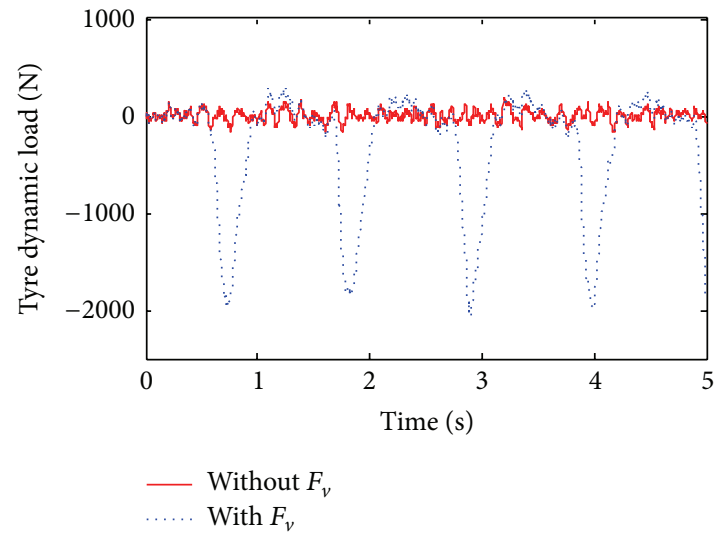

(b1)

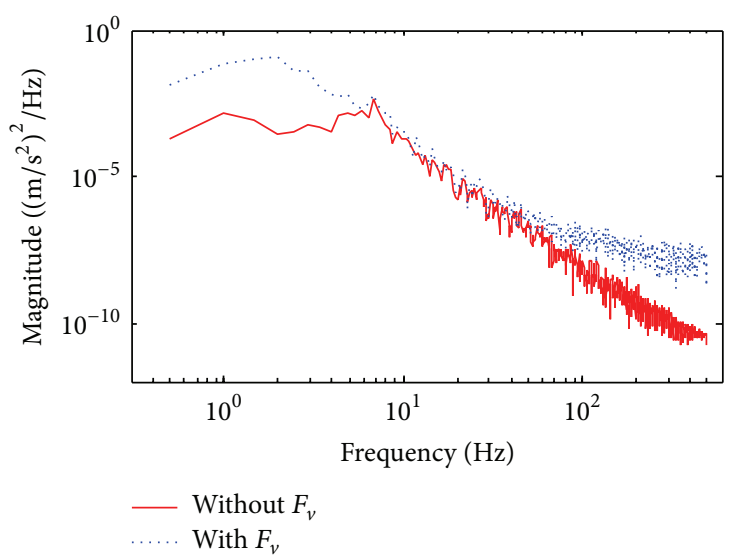

(a2)

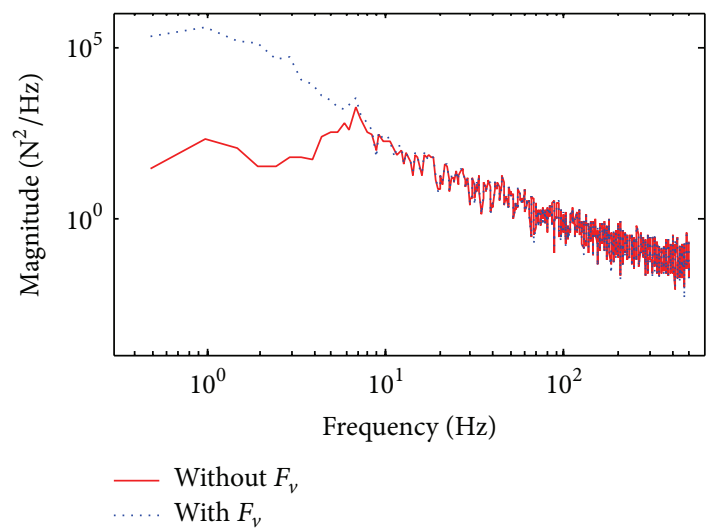

(b2)

FIGURE 8: Suspension response to SRM vertical force at velocity $2 \mathrm{~km} / \mathrm{h}$. (a1) Time history of sprung mass acceleration. (a2) PSD of sprung mass acceleration. (b1) Time history of tyre dynamic load. (b2) PSD of tyre dynamic load.

follow the desired references. The torque pulsations in SRM are relatively higher compared to sinusoidal machines due to the doubly salient structure of the motor. Many studies focus on torque ripple [41, 42], so we will not repeat it here.

SRM vertical force under rotor displacement $10 \%$ is shown in Figure 6. Figure 6(a1) shows the time response of SRM vertical force at vehicle speed $2 \mathrm{~km} / \mathrm{h}$. The peak value of SRM vertical force is nearly up to $2542 \mathrm{~N}$. Figure 6(a2) shows the power spectral density (PSD) of SRM vertical force at velocity $2 \mathrm{~km} / \mathrm{h}$ in the low frequency band $0 \sim 100 \mathrm{~Hz}$, which is concerned by vehicle suspension system. It can be seen that with the increase of excitation frequency the PSD of SRM vertical force is decreased dramatically. SRM vertical force is the mixed harmonic disturbance with the basis frequency of about $1.3 \mathrm{~Hz}$. Similarly, Figures 6(b) and 6(c) show the time history and PSD of SRM vertical force at $11 \mathrm{~km} / \mathrm{h}$ and $60 \mathrm{~km} / \mathrm{h}$, respectively. It can be seen that the fundamental frequency of SRM vertical force is about $7.5 \mathrm{~Hz}$ and $39 \mathrm{~Hz}$.

Figure 7 and Table 1 show SRM vertical force characteristics under different velocity and rotor displacement. It can be seen that SRM vertical force quickly increases as the vehicle velocity and rotor displacement increase. The effect of rotor relative displacement is more serious than vehicle speed. And
TABLE 1: SRM vertical force (unit: N).

\begin{tabular}{lccc}
\hline Velocity $(\mathrm{km} / \mathrm{h})$ & \multicolumn{3}{c}{ Rotor displacements (\%) } \\
\hline 20 & 5 & 10 & 15 \\
40 & 1321 & 2666 & 4043 \\
60 & 1523 & 3070 & 4572 \\
80 & 1800 & 3573 & 5428 \\
\hline
\end{tabular}

SRM vertical force reaches approximately $7000 \mathrm{~N}$ at vehicle $80 \mathrm{~km} / \mathrm{h}$ and rotor relative displacement $15 \%$, which imply that SRM effect on suspension performance is considerable. So it is essential to study the effects of SRM vertical force on IWM-EV suspension performance.

3.2. SRM Vertical Force Effect on Suspension Performance. The response of sprung mass acceleration and tyre dynamic load subject to SRM vertical force is selected to evaluate suspension performance. The vehicle speeds are $2 \mathrm{~km} / \mathrm{h}$, $11 \mathrm{~km} / \mathrm{h}$, and $60 \mathrm{~km} / \mathrm{h}$, respectively. The original reference 


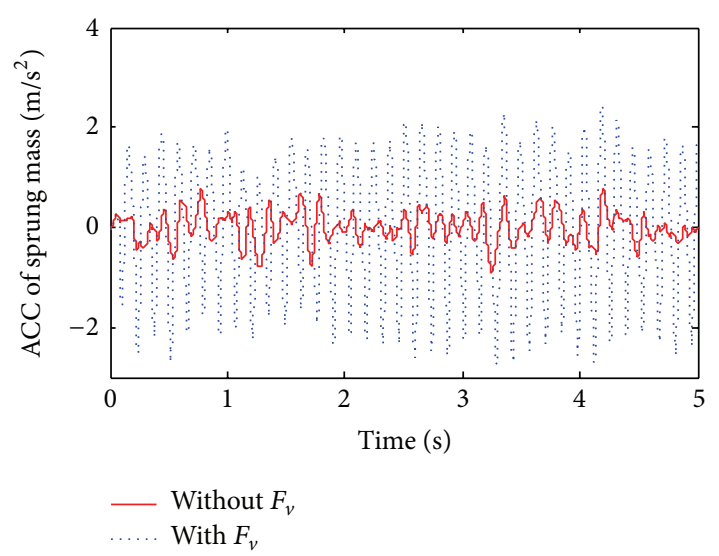

(a1)

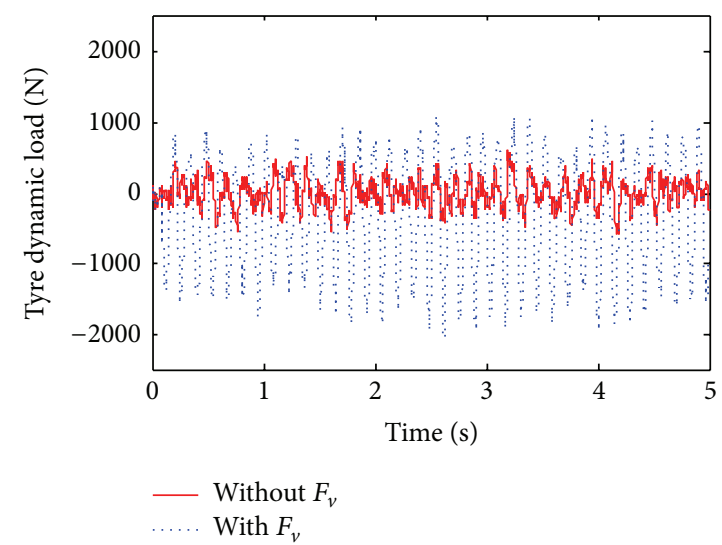

(b1)

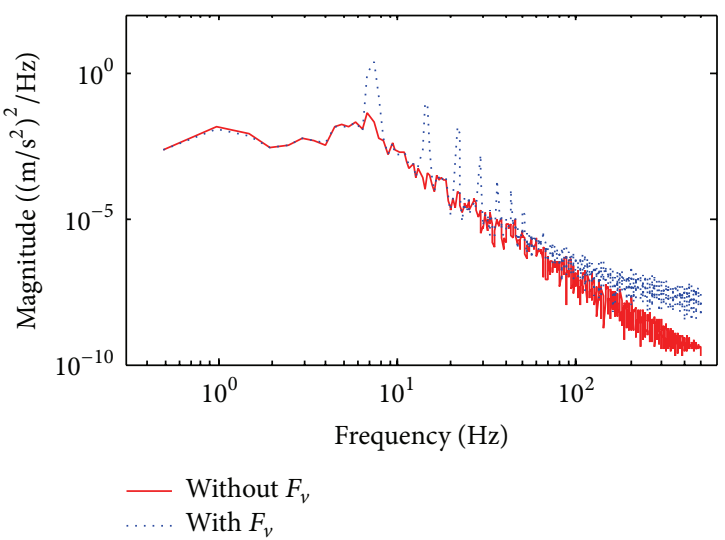

(a2)

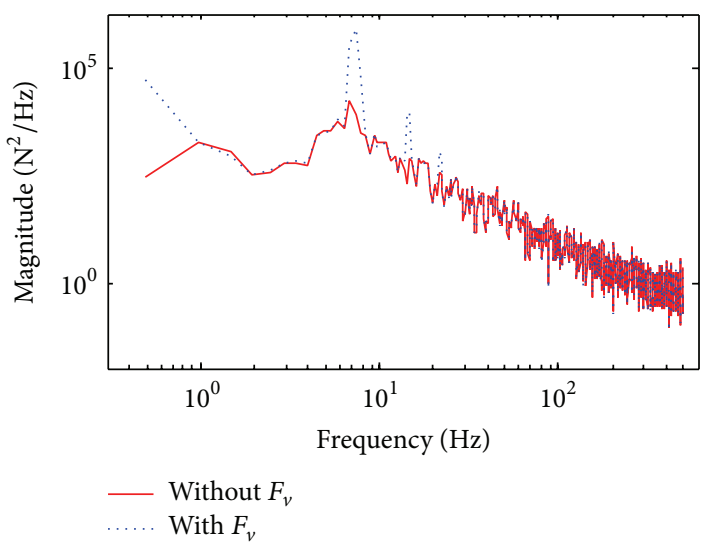

(b2)

FIGURE 9: Suspension response to SRM vertical force at velocity $11 \mathrm{~km} / \mathrm{h}$. (a1) Time history of sprung mass acceleration. (a2) PSD of sprung mass acceleration. (b1) Time history of tyre dynamic load. (b2) PSD of tyre dynamic load.

suspension does not take SRM vertical force into consideration. Computer simulations are performed to analyse SRM vertical force effect on vehicle suspension system.

According to the statistical characteristic of a real uneven road, the road velocity input can be modeled as a white noise, the power spectral density (PSD) of which is denoted as

$$
G_{w}(f)=4 \pi^{2} G\left(n_{0}\right) n_{0}^{2} v
$$

where $G\left(n_{0}\right)$ is road roughness coefficient, $n_{0}$ is reference spatial frequency, $v$ is vehicle forward velocity, and $f$ is timedomain frequency. In the studied case, $n_{0}=0.1$. For level B road, $G\left(n_{0}\right)$ is set at $64 \times 10^{-6} \mathrm{~m}^{3}$ which represents a smooth road surface. And for level C road, $G\left(n_{0}\right)$ is set at $256 \times 10^{-6} \mathrm{~m}^{3}$ which represents a terrible road surface.

Under level B road, the suspension response to SRM vertical force at vehicle speeds $2 \mathrm{~km} / \mathrm{h}, 11 \mathrm{~km} / \mathrm{h}$, and $60 \mathrm{~km} / \mathrm{h}$ is shown in Figures $8-9$. Figure 8 shows vehicle suspension under speed $2 \mathrm{~km} / \mathrm{h}$. From the time-domain results, it can be seen that SRM vertical force arouse a higher sprung mass acceleration. And the sprung mass resonance is nearly at the frequency $1.3 \mathrm{~Hz}$. Similarly, the vibration of wheel is severe due to sprung mass resonance.
Figure 9 shows the suspension response under speed $11 \mathrm{~km} / \mathrm{h}$. It can be seen that the wheel resonance is at frequency $7.5 \mathrm{~Hz}$, which increases the sprung mass vibration. And SRM vertical force generates sprung mass vibration peak at the fundamental frequency and multiple frequency, which means the vehicle comfort is greatly decreased at the vibration peak.

Figure 10 shows the suspension response under speed $60 \mathrm{~km} / \mathrm{h}$. It shows that SRM vertical force generates sprung mass vibration peak at the fundamental frequency $39 \mathrm{~Hz}$ and the multiple frequency. Although SRM vertical force effect on tyre dynamics is small in the frequencies above $10 \mathrm{~Hz}$, the effect is obvious in the frequencies below $1 \mathrm{~Hz}$ as shown in Figure 10(b2).

According to the above analysis, it can be seen that SRM vertical force greatly increases the vibration of vehicle suspension system. So it is an important factor that cannot be neglected in IWM-EV suspension system research.

\section{FxLMS Controller Design}

FxLMS controller is employed to suppress the vibration caused by SRM vertical force excitation. Due to its simplicity 


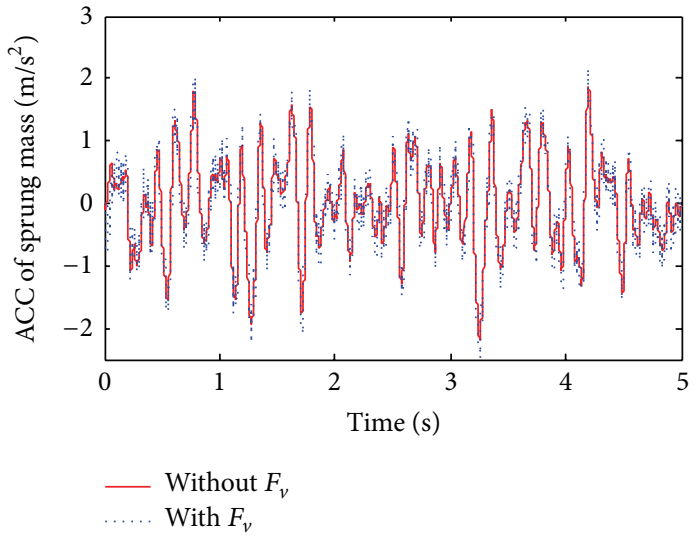

(a1)

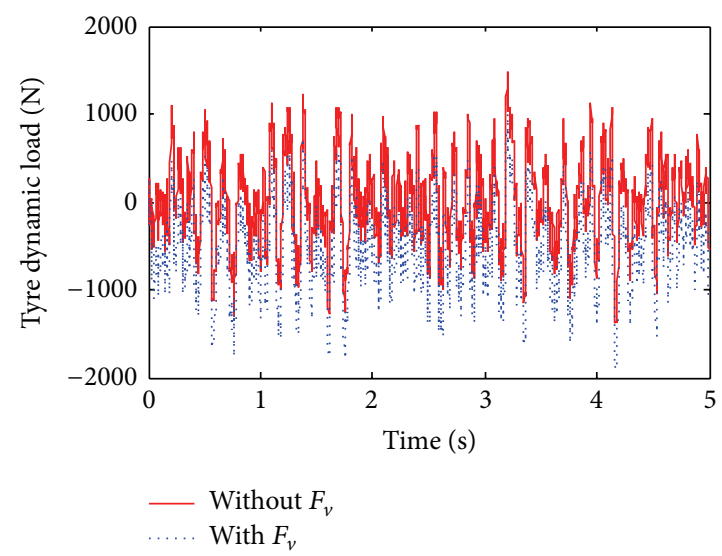

(b1)

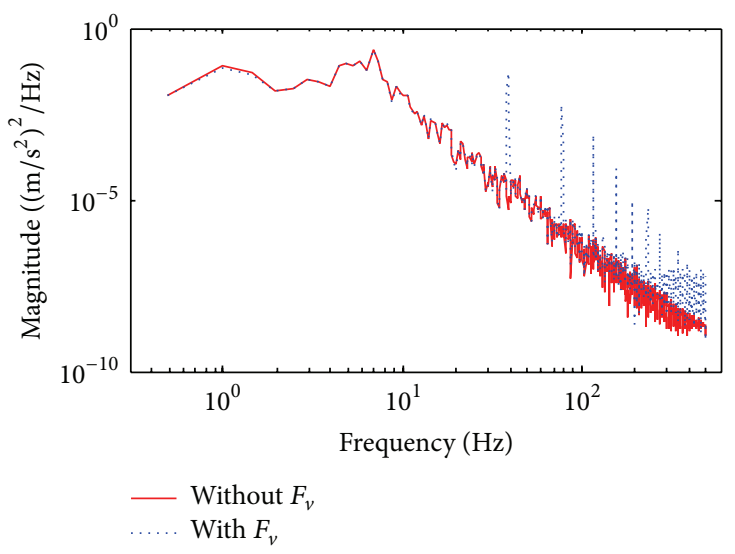

(a2)

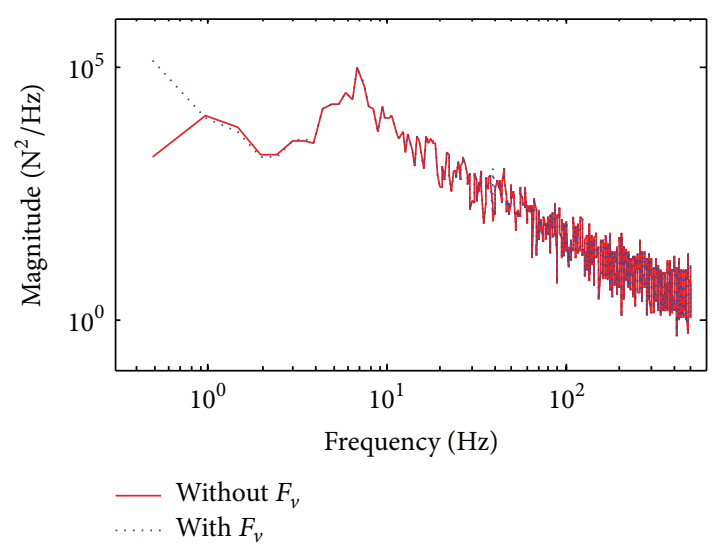

(b2)

FIGURE 10: Suspension response to SRM vertical force at velocity $60 \mathrm{~km} / \mathrm{h}$. (a1) Time history of sprung mass acceleration. (a2) PSD of sprung mass acceleration. (b1) Time history of tyre dynamic load. (b2) PSD of tyre dynamic load.

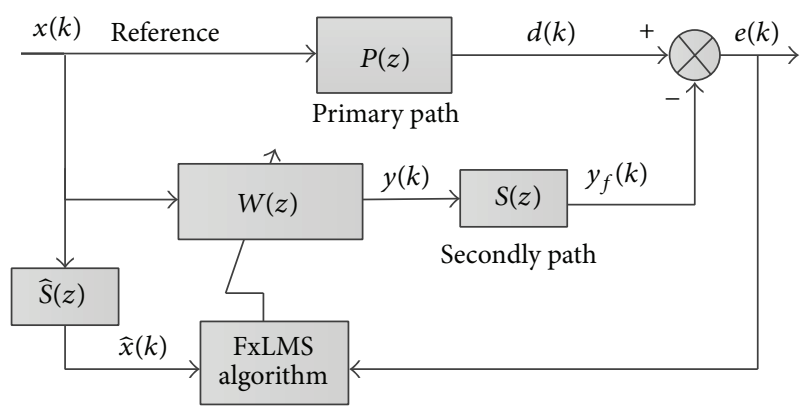

FIGURE 11: The structure of FxLMS algorithm.

and stable reliable operation, the FxLMS is one of the most often applied strategies in active noise control [43-45]. It is adjusting an adaptive filter in a feedforward structure; therefore, it is especially suited for the damping of periodic disturbances. And the analysis above shows that SRM vertical force is periodic excitation, so the FxLMS algorithms are adopted to improve suspension performance.

The structure of the FxLMS algorithm is shown in Figure 11, following the notation of [43]. The cancellation of the disturbance signal $d(k)$ is achieved by subtracting the signal $y_{f}(k)$. The cancellation of the disturbance signal is achieved by subtracting the signal generated by the secondary path $(z)$. In typical active noise control applications, the secondary path includes an actuator driven by the output signal $y(k)$ of the adaptive filter $W(z)$. The model $\widehat{S}(z)$ of the secondary path is applied to compensate for the negative effects of $S(z)$ on the stability of the algorithm. In the following, it is assumed that $\widehat{S}(z)=S(z)$. Since the input signal of $W(z)$ is the reference signal $x(k)$ measured at the source of the disturbing vibration, a feedforward configuration is realized.

The adaptation of $W(z)$ is performed by an algorithm of FxLMS structure, which adjusts the coefficients by applying the recursive formula

$$
w(k+1)=w(k)+\mu x(k) e(k),
$$

where $x(k)=\left[\begin{array}{llll}x(0) & x(1) & \cdots & x(k-l)\end{array}\right]^{T}$ and $\mu$ denotes a step size, which influences the convergence speed of the algorithm.

The basic formula of the error signal is given by

$$
e(k)=d(k)+w^{T}(k) x(k) .
$$




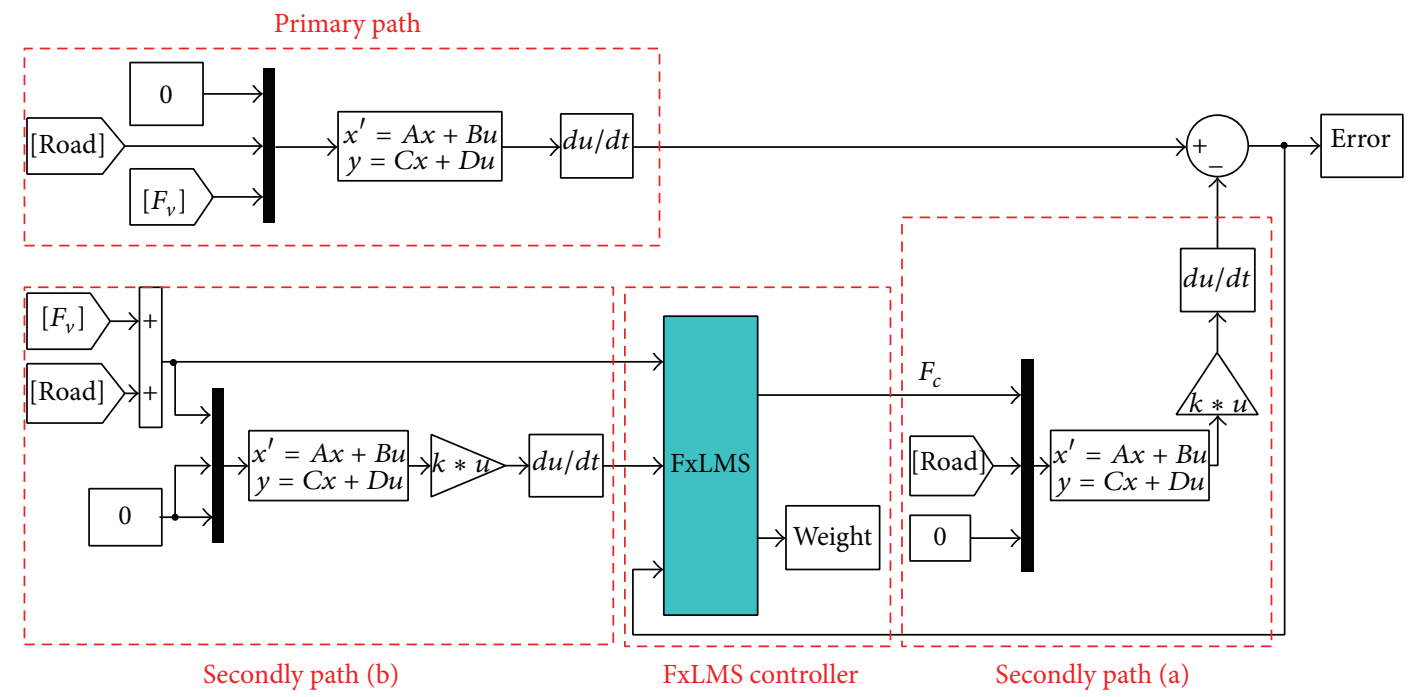

FIgURE 12: The Simulink model for FxLMS controller.

The output vector is

$$
y(k)=w^{T}(k) x(k) .
$$

According to (13)-(15), the FxLMS does not include the calculations of square, mean, and differential values. So the algorithm is simple and efficient. FxLMS adaptive method with adjusting the weight coefficient can adapt the output to the input. The algorithm has been applied in the study of the active control of the engine vibration, and the effect is very good [42].

In order to design the FxLMS controller based on vehicle active suspension system, the state space equations of suspension dynamics equations (1) in matrix form are given by

$$
\begin{aligned}
& \dot{X}=A X+B U, \\
& Y=C X+D U,
\end{aligned}
$$

where the state vector $X$ is defined as $X=\left[\begin{array}{llll}z_{s} & \dot{z}_{s} & z_{u} & \dot{z}_{u}\end{array}\right]^{T}$, the input vector $u$ is defined as $u=\left[\begin{array}{lll}F_{c} & q & F_{v}\end{array}\right]^{T}$, the output vector $Y$ is equal to $X$, the parameter matrices $A$ and $B$ are defined as

$$
\begin{aligned}
A & =\left[\begin{array}{cccc}
0 & 1 & 0 & 0 \\
-\frac{k_{s}}{m_{s}} & -\frac{c_{s}}{m_{s}} & \frac{k_{s}}{m_{s}} & \frac{c_{s}}{m_{s}} \\
0 & 0 & 0 & 1 \\
\frac{k_{s}}{m_{u}} & \frac{c_{s}}{m_{u}} & -\frac{k_{s}+k_{t}}{m_{u}} & -\frac{c_{s}}{m_{u}}
\end{array}\right], \\
B & =\left[\begin{array}{ccc}
0 & 0 & 0 \\
-\frac{1}{m_{s}} & 0 & 0 \\
0 & 0 & 0 \\
\frac{1}{m_{u}} & \frac{k_{t}}{m_{u}} & -\frac{1}{m_{u}}
\end{array}\right],
\end{aligned}
$$

the parameter matrix $C$ is the four by four identity matrix, and matrix $D$ is a four by three matrix of zeros.
Design the FxLMS controller based on vehicle active suspension system as follows. The reference signal $x$ is defined as the sum of SRM vertical force and road excitement $x(k)=$ $F_{v}(k)+q(k)$. The cancellation of the disturbance signal $d(k)$ is the acceleration of unsprung mass $\ddot{z}_{u}(k)$. The primary path model $P(z)$ is equal to the secondary path $S(z)$, which is the state space equations of vehicle suspension system as described by (16). According to (13)-(15), the FxLMS controller based on active suspension can be described as

$$
\begin{gathered}
w(k+1)=w(k)+\mu\left[F_{v}(k)+q(k)\right] e(k) \\
e(k)=\ddot{z}_{u}(k)+w^{T}(k)\left[F_{v}(k)+q(k)\right] \\
F_{c}(k)=w^{T}(k)\left[F_{v}(k)+q(k)\right] .
\end{gathered}
$$

The Simulink model for FxLMS controller is illustrated by Figure 12. The input reference signal of the primary path is road excitation $q$ and SRM vertical force $F_{v}$ which is achieved by SRM controller. And the output is the acceleration of vehicle unsprung mass $\ddot{z}_{u}$. The input of secondary path model (a) is active control force $F_{c}$ which is achieved by FxLMS controller. The output of the secondary path model (a) is $\ddot{z}_{u}^{\prime}$ which is compared with the output of primary path $\ddot{z}_{u}$ to get the control error. Secondary path model (b) is used to compensate for the negative effects of secondary path model (a). If there is no motor eccentricity at all, SRM vertical force becomes zero. There are many researches on vehicle suspension system which take no account of SRM vertical force $[46,47]$, so we will not repeat it here.

\section{Results and Discussion}

Computer simulations are performed to verify the effectiveness of the FxLMS controller designed in this study, with level $\mathrm{B}$ and level $\mathrm{C}$ road input. The suspension performance under FxLMS control is analysed at vehicle velocities $2 \mathrm{~km} / \mathrm{h}$, $11 \mathrm{~km} / \mathrm{h}$, and $60 \mathrm{~km} / \mathrm{h}$, respectively. The PSD of different 

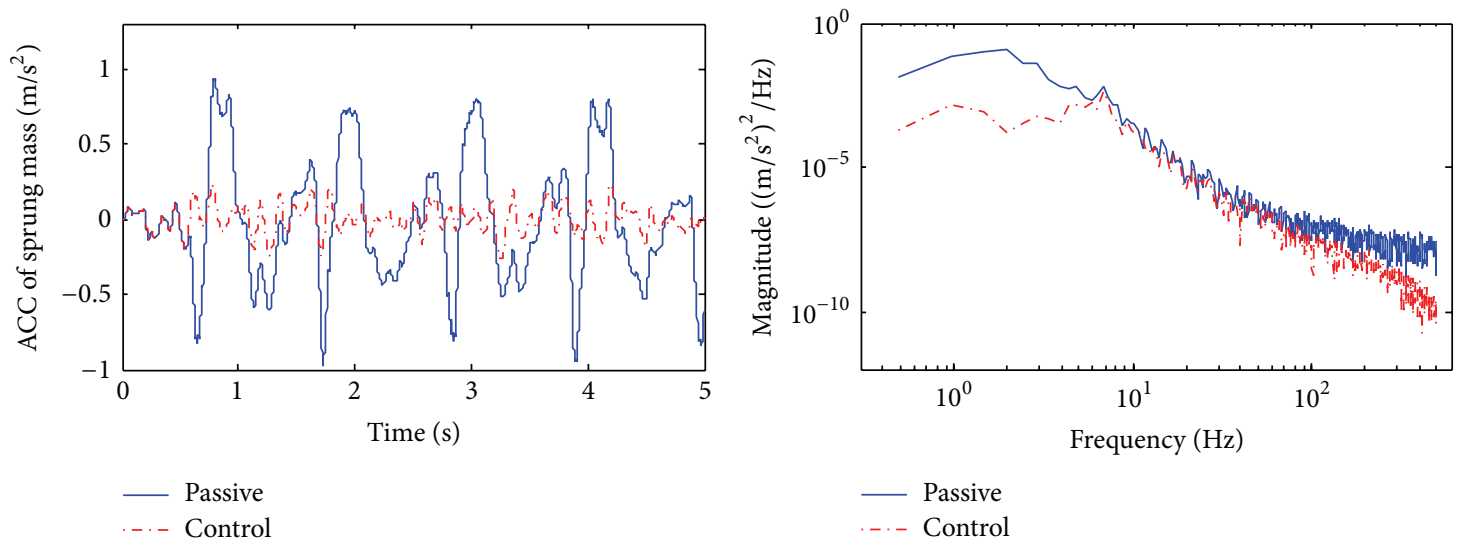

(a1)

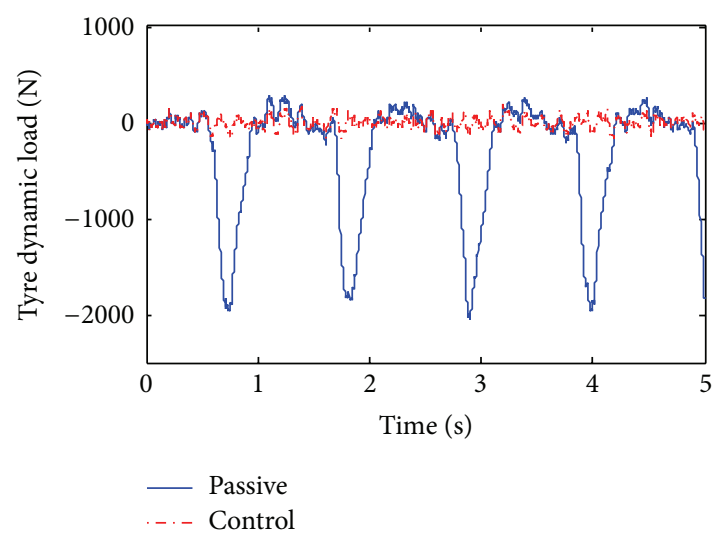

(b1)

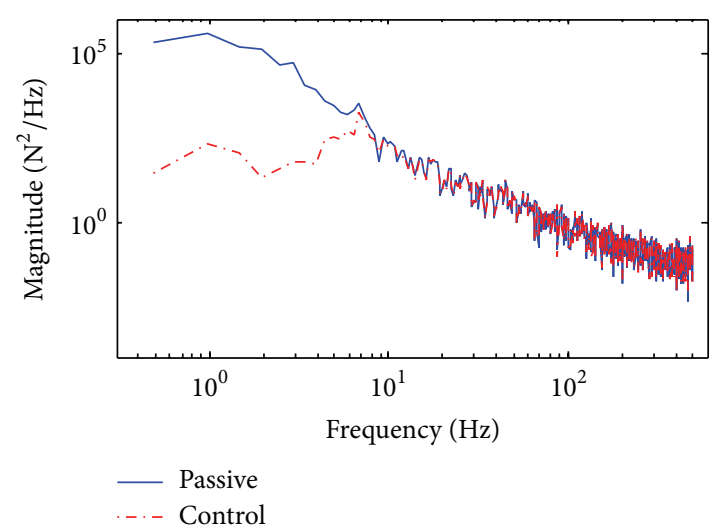

(b2)

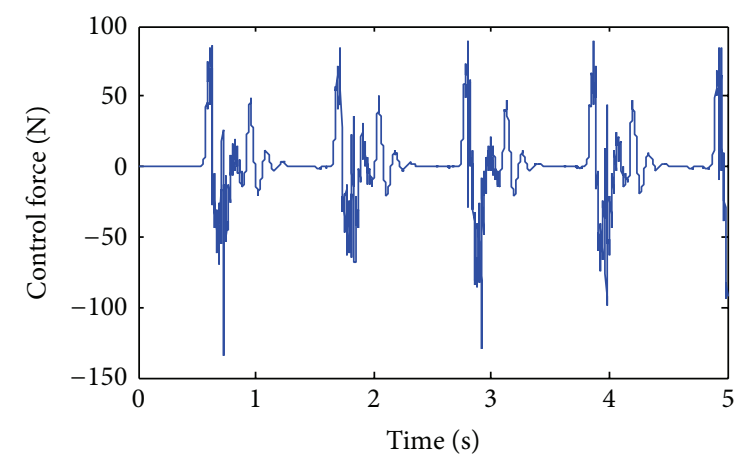

(c1)

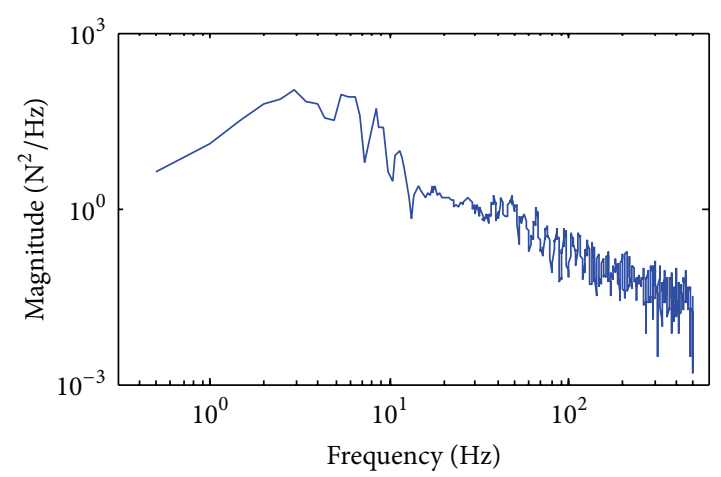

(c2)

FIGURE 13: Suspension performance under FxLMS control at velocity $2 \mathrm{~km} / \mathrm{h}$. (a1) Time history of sprung mass acceleration. (a2) PSD of sprung mass acceleration. (b1) Time history of tyre dynamic load. (b2) PSD of tyre dynamic load. (c1) Time history of suspension control force. (c2) PSD of suspension control force.

suspension performances for FxLMS controller is compared with the passive system in which the control force is zero, $F_{c}=0$. Figures 13, 14, and 15 illustrate vehicle suspension performance under FxLMS controller at different velocities.

From Figure 13(a), it can be seen that, under the sprung mass resonance case, better comfort can be achieved by FxLMS control in low frequencies $(0-6 \mathrm{~Hz})$ compared with the passive system. Moreover, the vibration of wheel under control is decreased in the low frequencies as shown in Figure 13(b). The PSD of active suspension control force is also presented in Figure 13(c).
From Figure 14(a), it can be seen that better comfort can be achieved by FxLMS control in medium and high frequencies $(6-8 \mathrm{~Hz}$ and $8-50 \mathrm{~Hz})$ under the wheel resonance case. And the vibration peaks at SRM vertical force fundamental frequency and multiple frequency decreases dramatically. Besides that, the PSD of tyre dynamics is decreased obviously at the vibration peaks and the frequency below $1 \mathrm{~Hz}$, which means the vehicle road-holding ability is improved compared to the passive system.

Figure 15 shows the suspension performance under FxLMS control at velocity $60 \mathrm{~km} / \mathrm{h}$. From Figure 15(a), it 


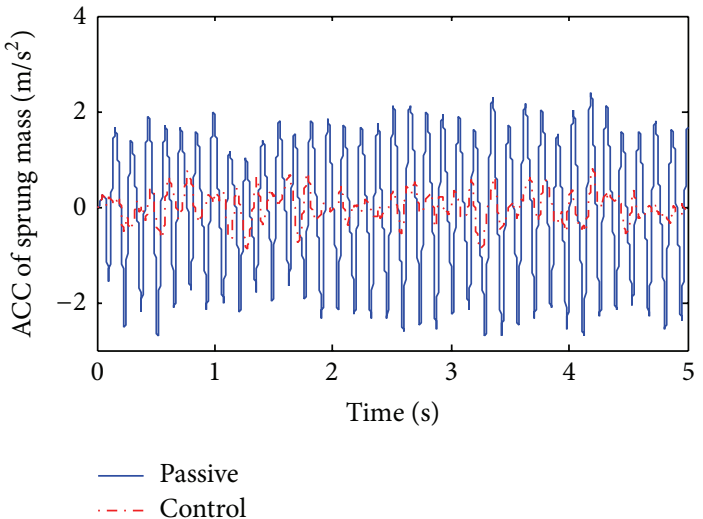

(a1)

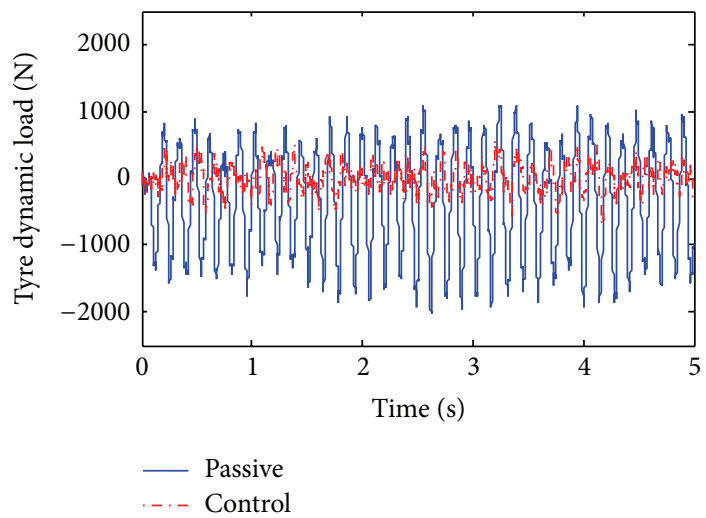

(b1)

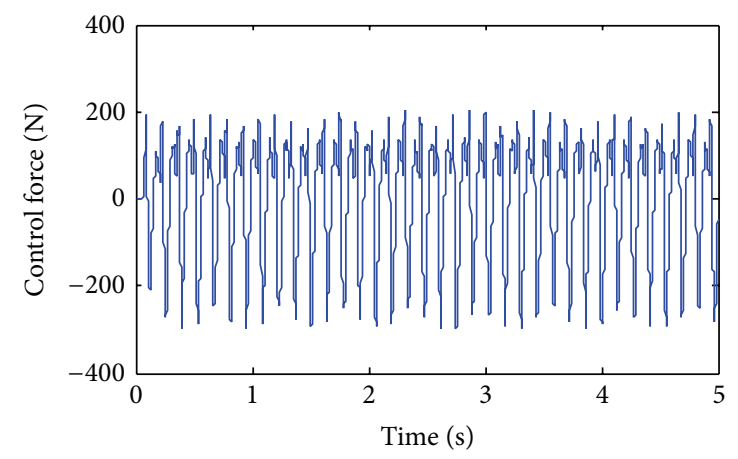

(c1)

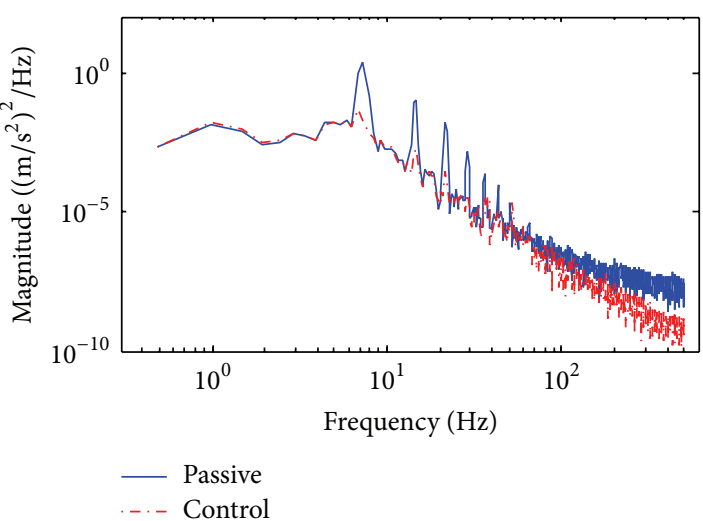

(a2)

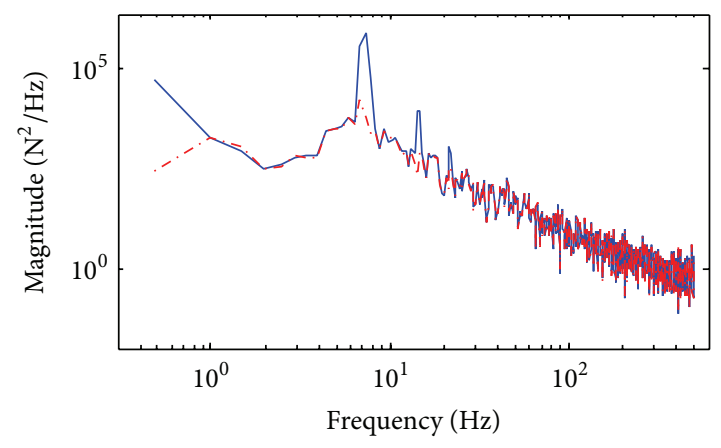

- Passive

-..- Control

(b2)

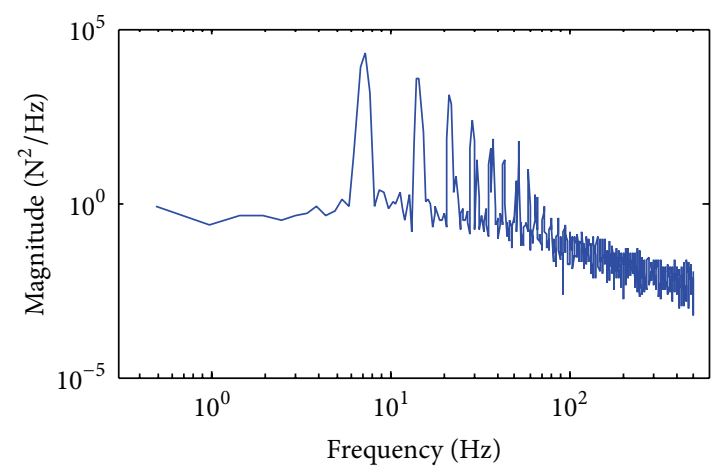

(c2)

FIGURE 14: Suspension performance under FxLMS control at velocity $11 \mathrm{~km} / \mathrm{h}$. (a1) Time history of sprung mass acceleration. (a2) PSD of sprung mass acceleration. (b1) Time history of tyre dynamic load. (b2) PSD of tyre dynamic load. (c1) Time history of suspension control force. (c2) PSD of suspension control force.

can be seen that there are different degree decrease at the vibration peaks. A better road-holding ability can be achieved in the low frequencies below $1 \mathrm{~Hz}$.

Table 2 summaries the root mean squared (RMS) value of sprung mass under level $B$ and level $C$ road. It can be seen that the vibration of sprung mass decreases dramatically compared with the passive system under two resonance cases. And the acceleration of sprung mass under FxLMS control decreases to a certain degree at $60 \mathrm{~km} / \mathrm{h}$ which is the no-resonance case. Compared with the resonance cases, the controller is not very powerful under the nonresonance conditions. It is because that SRM vertical force has a more significant effect on the vibration of vehicle body and wheel under the resonance cases. Collectively, we can say the suspension performance is improved under FxLMS control.

\section{Conclusions}

SRM are well suited for in-wheel motor due to their high torque, high efficiency, and excellent power-speed characteristics. However, SRM used as in-wheel motor brings new problems: SRM vertical force excitation. Like road excitation, SRM vertical force excitation also has great effect on suspension performance. In this paper, the characteristics of 

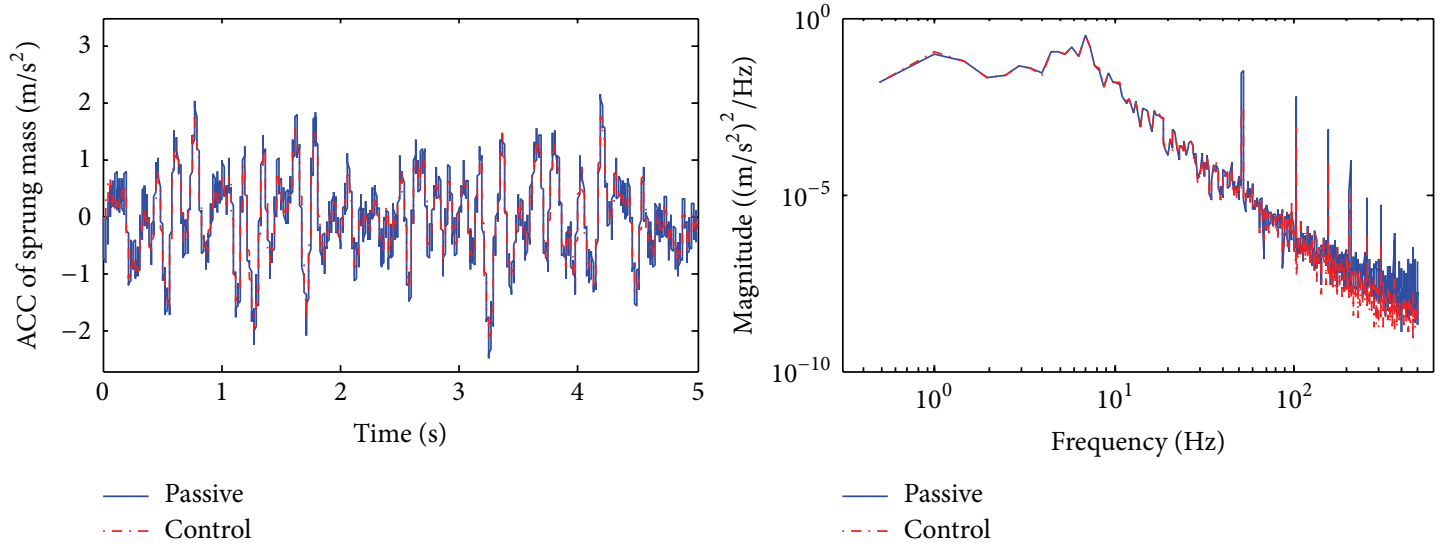

(a1)
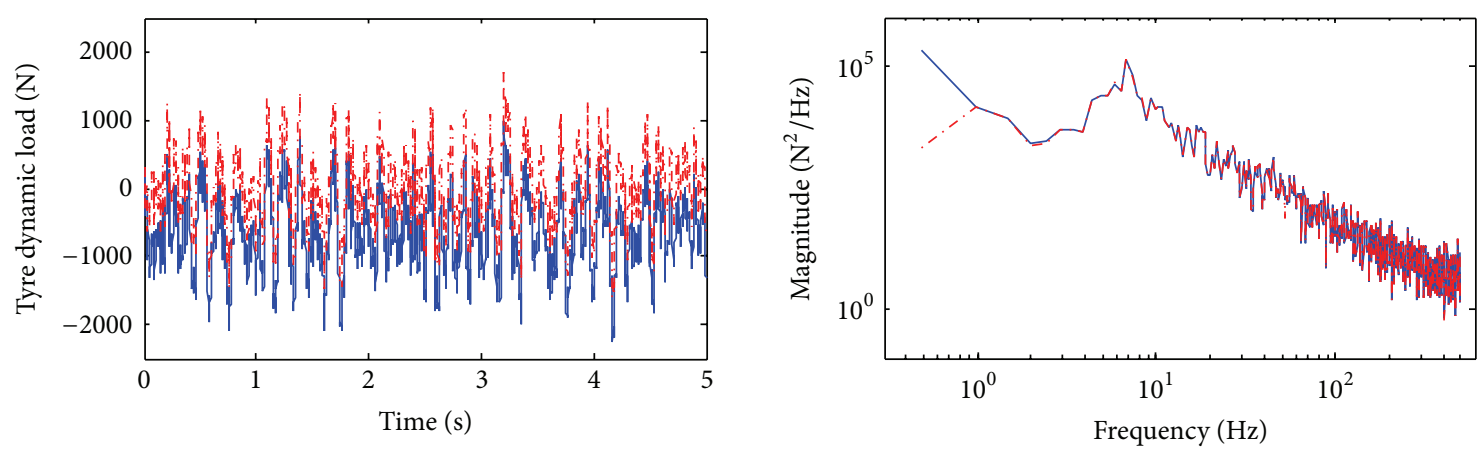

_. Passive
.. - Control

(b1)

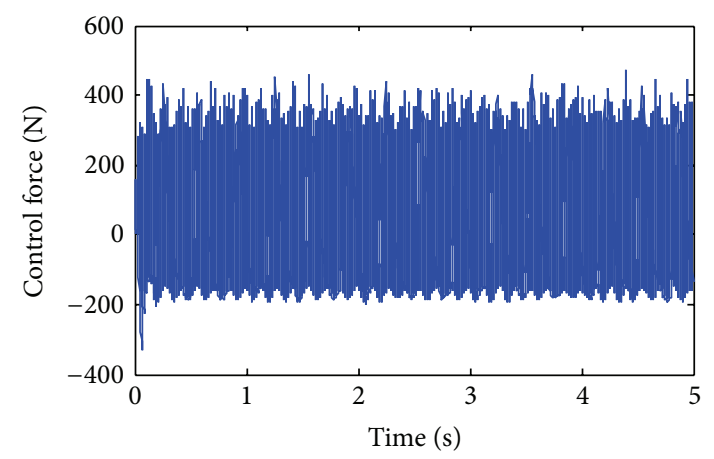

(c1)
- Passive

...- Control

(b2)

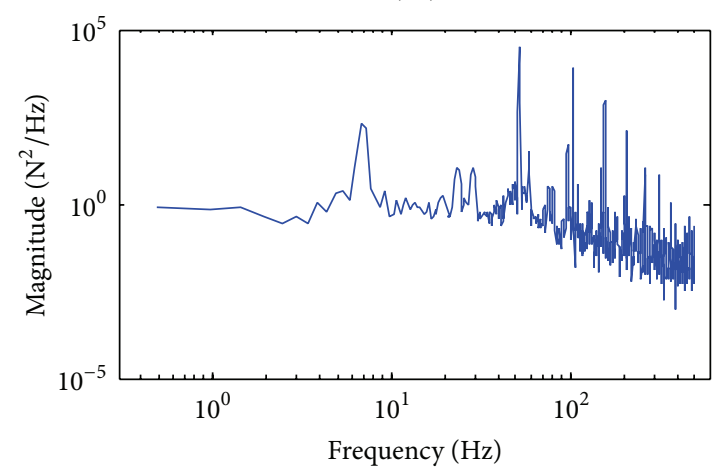

(c2)

FIGURE 15: Suspension performance under LMS control at velocity $60 \mathrm{~km} / \mathrm{h}$. (a1) Time history of sprung mass acceleration. (a2) PSD of sprung mass acceleration. (b1) Time history of tyre dynamic load. (b2) PSD of tyre dynamic load. (c1) Time history of suspension control force. (c2) PSD of suspension control force.

TABLE 2: Comparison of RMS values of sprung mass acceleration.

\begin{tabular}{|c|c|c|c|c|c|c|}
\hline & \multicolumn{3}{|c|}{ Level B road } & \multicolumn{3}{|c|}{ Level C road } \\
\hline & $2 \mathrm{~km} / \mathrm{h}$ & $11 \mathrm{~km} / \mathrm{h}$ & $60 \mathrm{~km} / \mathrm{h}$ & $2 \mathrm{~km} / \mathrm{h}$ & $11 \mathrm{~km} / \mathrm{h}$ & $60 \mathrm{~km} / \mathrm{h}$ \\
\hline Passive & 0.41 & 1.33 & 0.75 & 0.45 & 1.42 & 1.46 \\
\hline Control & 0.09 & 0.31 & 0.66 & 0.18 & 0.62 & 1.31 \\
\hline Relative change & $77.19 \%$ & $76.59 \%$ & $12.56 \%$ & $58.40 \%$ & $56.32 \%$ & $10.27 \%$ \\
\hline
\end{tabular}


TABLE 3: Parameters of IWM-EV active suspension.

\begin{tabular}{lccc}
\hline Definition & Symbol & Units & Value \\
\hline Sprung mass & $m_{s}$ & $\mathrm{~kg}$ & 338 \\
Unsprung mass & $m_{u}$ & $\mathrm{~kg}$ & 78 \\
Suspension stiffness & $k_{s}$ & $\mathrm{~N} / \mathrm{m}$ & 22500 \\
Tyre stiffness & $k_{t}$ & $\mathrm{~N} / \mathrm{m}$ & 150000 \\
Suspension damping & $d_{p}$ & $\mathrm{~N} \cdot \mathrm{s} / \mathrm{m}$ & 1695 \\
\hline
\end{tabular}

TABLE 4: Out-rotor 6/4 SRM nomenclature and value.

\begin{tabular}{lc}
\hline Definition & Value \\
\hline Number of stator poles & 6 \\
Number of rotor poles & 4 \\
Stator pole arc angle & 29 degrees \\
Rotor pole arc angle & 30 degrees \\
Air gap & $0.25 \mathrm{~mm}$ \\
Outer diameter of rotor & $31.2 \mathrm{~mm}$ \\
Outer diameter of stator & $18.5 \mathrm{~mm}$ \\
Length of stack & $6.3 \mathrm{~mm}$ \\
Minimum inductance & $0.0019 \mathrm{H}$ \\
Maximum inductance & $0.0318 \mathrm{H}$ \\
Saturated inductance & $0.0013 \mathrm{H}$ \\
Maximum flux linkage & $0.9 \mathrm{~Wb}$ \\
Motor rated voltage & $240 \mathrm{~V}$ \\
Motor rated power & $8 \mathrm{~kW}$ \\
Motor rated speed & $2000 \mathrm{rpm}$ \\
\hline
\end{tabular}

SRM vertical force and the effect on IWM-EV suspension performance are discussed. In order to suppress SRM vertical force and improve suspension performance, the FxLMS controller is investigated in this paper. And the important findings are as follows.

(1) SRM vertical force is an important factor to suspension performance analysis. It is very common due to the manufacture tolerance and SRM work condition. And the frequency of SRM vertical force covers the natural frequency of passive suspension system, which will easily induce suspension resonance, especially in vehicle start-up and low speed conditions. So SRM vertical force cannot be neglected in the analysis of suspension performance.

(2) The effect of SRM vertical force on suspension performance is considerable. Under sprung mass resonance and wheel resonance severe cases, the acceleration of vehicle suspension increases dramatically. The wheel vibration also increases greatly.

(3) Aiming at the above-mentioned problems, FxLMS controller is proposed to improve suspension performance. The FxLMS controller is based on active suspensions which can generate the controllable force to suppress SRM vertical force. Under FxLMS control, the sprung mass acceleration is reduced obviously compared with passive system. The results show that FxLMS control is effective. And it is feasible to take advantage of active suspensions to reduce the effect of SRM vertical force.

This paper is focused on the analysis of SRM vertical force proposition of SRM vertical force suppression method to improve suspension performance. However, the effects of vehicle acceleration or braking, the yaw moment induced by SRM vertical force, and the mechanical connection parts between SRM and wheel are not considered, since the action mechanism of these factors is implicit and intricate. A more comprehensive research is needed to make a thorough investigation on SRM vertical force. SRM vertical force suppression methods, for example, semiactive suspension solution, and experiments need to be further studied. These factors will be taken into account in the next work.

\section{Conflict of Interests}

The authors declare that they have no conflict of interests regarding the publication of this paper.

\section{Acknowledgments}

This research is supported by the National Natural Science Foundation of China (Grant nos. 51275541 and 51005256), National Nature Science Foundation of Chongqing (Grant no. cstc2013jjB0022), and Foundation of State Key Laboratory of Mechanical Transmission (Grant no. SKLMT-ZZKT-2012 ZD 06).

\section{References}

[1] S. Murata, "Innovation by in-wheel-motor drive unit," Vehicle System Dynamics, vol. 50, no. 6, pp. 807-830, 2012.

[2] E. Katsuyama, "Decoupled 3D moment control using in-wheel motors," Vehicle System Dynamics, vol. 51, no. 1, pp. 18-31, 2013.

[3] K. Nam, H. Fujimoto, and Y. Hori, "Lateral stability control of in-wheel-motor-driven electric vehicles based on sideslip angle estimation using lateral tire force sensors," IEEE Transactions on Vehicular Technology, vol. 61, no. 5, pp. 1972-1985, 2012.

[4] X. D. Xue, K. W. E. Cheng, T. W. Ng, and N. C. Cheung, "Multiobjective optimization design of in-wheel switched reluctance motors in electric vehicles," IEEE Transactions on Industrial Electronics, vol. 57, no. 9, pp. 2980-2987, 2010.

[5] J. de Santiago, H. Bernhoff, B. Ekergård et al., "Electrical motor drivelines in commercial all-electric vehicles: a review," IEEE Transactions on Vehicular Technology, vol. 61, no. 2, pp. 475-484, 2012.

[6] K. Urase, K. Kiyota, H. Sugimoto, and A. Chiba, "Design of a switched reluctance generator competitive with the IPM generator in hybrid electrical vehicles," in Proceedings of the 15th International Conference on Electrical Machines and Systems (ICEMS '12), pp. 1-6, Sapporo, Japan, October 2012.

[7] K. M. Rahman, B. Fahimi, G. Suresh, A. V. Rajarathnam, and M. Ehsani, "Advantages of switched reluctance motor applications to EV and HEV: design and control issues," IEEE Transactions on Industry Applications, vol. 36, no. 1, pp. 111-121, 2000.

[8] Y. Gao and M. D. McCulloch, "A review of high power density switched reluctance machines suitable for automotive applications," in Proceedings of the 20th International Conference 
on Electrical Machines (ICEM '12), pp. 2610-2614, September 2012.

[9] H. Torkaman, E. Afjei, and H. Amiri, "Dynamic eccentricity fault diagnosis in switched reluctance motor," in Proceedings of the International Symposium on Power Electronics, Electrical Drives, Automation and Motion (SPEEDAM '10), pp. 519-522, Taormina, Italy, June 2010.

[10] F. Marques dos Santos, J. Anthonis, and F. Naclerio, "Multiphysics NVH modeling: simulation of a switched reluctance motor drivetrain for an electric vehicle," IEEE Transactions on Industrial Electronics, vol. 61, no. 1, pp. 469-476.

[11] M. Divandari and A. Dadpour, "Radial force and torque ripple optimization for acoustic noise reduction of SRM drives via fuzzy logic control," in Proceedings of the 9th IEEE/IAS International Conference on Industry Applications (INDUSCON '10), pp. 1-6, Sao Paulo, Brazil, November 2010.

[12] E. Afjei and H. Torkaman, "Airgap eccentricity fault diagnosis in switched reluctance motor," in Proceedings of the 1st Power Electronics and Drives, Systems and Technologies Conference (PEDSTC '10), pp. 290-294, Tehran, Iran, February 2010.

[13] M. N. Anwar, I. Husain, and A. V. Radun, "A comprehensive design methodology for switched reluctance machines," IEEE Transactions on Industry Applications, vol. 37, no. 6, pp. 16841692, 2001.

[14] K. Kiyota and A. Chiba, "Design of switched reluctance motor competitive to $60-\mathrm{kW}$ IPMSM in third-generation hybrid electric vehicle," IEEE Transactions on Industry Applications, vol. 48, no. 6, pp. 2303-2309, 2012.

[15] B. Fahimi, G. Suresh, and M. Ehsani, "Design considerations of switched reluctance motors: vibration and control issues," in Proceedings of the 1999 IEEE Industry Applications Conference, pp. 2259-2266, October 1999.

[16] C. Sikder, I. Husain, and Y. Sozer, "Switched reluctance generator controls for optimal power generation with current regulation," in Proceedings of the 4th Annual IEEE Energy Conversion Congress and Exposition (ECCE '12), pp. 4322-4329, Raleigh, NC, USA, September 2012.

[17] H. Inagaki, H. Kato, and H. Kuzuya, "Drive train vibration and acoustic noise reduction control of switched reluctance motor for electric vehicle," SAE Technical Papers 6183176, SAE.

[18] F. L. M. dos Santos, J. Anthonis, and H. van der Auweraer, "Multiphysics thermal and NVH modeling: integrated simulation of a switched reluctance motor drivetrain for an electric vehicle," in Proceedings of the IEEE International Electric Vehicle Conference (IEVC '12), pp. 1-7, March 2012.

[19] J. Li and Y. Cho, "Dynamic reduction of unbalanced magnetic force and vibration in switched reluctance motor by the parallel paths in windings," Mathematics and Computers in Simulation, vol. 81, no. 2, pp. 407-419, 2010.

[20] B. M. Ebrahimi, J. Faiz, and M. J. Roshtkhari, "Static-, dynamic, and mixed-eccentricity fault diagnoses in permanent-magnet synchronous motors," IEEE Transactions on Industrial Electronics, vol. 56, no. 11, pp. 4727-4739, 2009.

[21] J. Faiz and S. Pakdelian, "Finite element analysis of switched reluctance motor under dynamic eccentricity fault," in Proceedings of the 12th International Power Electronics and Motion Control Conference, pp. 1042-1046, September 2006.

[22] N. K. Sheth and K. R. Rajagopal, "Effects of nonuniform airgap on the torque characteristics of a switched reluctance motor," IEEE Transactions on Magnetics, vol. 40, no. 4, pp. 2032-2034, 2004.
[23] I. Husain and A. Radun, "Unbalanced force calculation in switched-reluctance machines," IEEE Transactions on Magnetics, vol. 36, no. 1, pp. 330-338, 2000.

[24] N. K. Sheth and K. R. Rajagopal, "Variations in overall developed torque of a switched reluctance motor with airgap nonuniformity," IEEE Transactions on Magnetics, vol. 41, no. 10, pp. 3973-3975, 2005.

[25] K. R. Rajagopal, B. Singh, and B. P. Singh, "Static torque profiles of a hybrid stepper motor having relative eccentricity between stator and rotor axes," Journal of Applied Physics, vol. 93, no. 10, pp. 8701-8703, 2003.

[26] S. B. A. Kashem, M. Ektesabi, and R. Nagarajah, "Comparison between different sets of suspension parameters and introduction of new modified skyhook control strategy incorporating varying road condition," Vehicle System Dynamics, vol. 50, no. 7, pp. 1173-1190, 2012.

[27] R. D. Naik and P. M. Singru, "Resonance, stability and chaotic vibration of a quarter-car vehicle model with time-delay feedback," Communications in Nonlinear Science and Numerical Simulation, vol. 16, no. 8, pp. 3397-3410, 2011.

[28] B. L. J. Gysen, J. J. H. Paulides, J. L. G. Janssen, and E. A. Lomonova, "Active electromagnetic suspension system for improved vehicle dynamics," IEEE Transactions on Vehicular Technology, vol. 59, no. 3, pp. 1156-1163, 2010.

[29] N. H. Amer, R. Ramli, H. M. Isa, W. N. L. Mahadi, and M. A. Z. Abidin, "A review of energy regeneration capabilities in controllable suspension for passengers'car," Energy Education Science and Technology A: Energy Science and Research, vol. 30, no. 1, pp. 143-158, 2012.

[30] D. A. Torrey, X.-M. Niu, and E. J. Unkauf, "Analytical modelling of variable-reluctance machine magnetisation characteristics," IEE Proceedings: Electric Power Applications, vol. 142, no. 1, pp. 14-22, 1995.

[31] H. Le-Huy and P. Brunelle, "A versatile nonlinear switched reluctance motor model in simulink using realistic and analytical magnetization characteristics," in Proceedings of the 31st Annual Conference of IEEE Industrial Electronics Society, pp. 1556-1561, Raleigh, NC, USA, November 2005.

[32] D. Cajander and H. Le-Huy, "Design and optimization of a torque controller for a switched reluctance motor drive for electric vehicles by simulation," Mathematics and Computers in Simulation, vol. 71, no. 4-6, pp. 333-344, 2006.

[33] R. Krishnan, Switched Reluctance Motor Drives-Modeling, Simulation, Analysis, Design, and Applications, CRC press, Boca Raton, Fla, USA, 2001.

[34] J. Liang, D.-H. Lee, and J.-W. Ahn, "Direct instantaneous torque control of switched reluctance machines using 4-level converters," IET Electric Power Applications, vol. 3, no. 4, pp. 313-323, 2009.

[35] N. R. Garrigan, W. L. Soong, and C. M. Stephens, "Radial force characteristics of a switched reluctance machine," in Proceedings of the 1999 IEEE Industry Applications Conference, pp. 22502258, Phoenix, Ariz, USA, October 1999.

[36] K. T. Chau, D. Zhang, J. Z. Jiang, C. Liu, and Y. Zhang, “Design of a magnetic-geared outer-rotor permanent-magnet brushless motor for electric vehicles," IEEE Transactions on Magnetics, vol. 43, no. 6, pp. 2504-2506, 2007.

[37] L. Jiongkang, K. W. E. Cheng, and Z. Zhu, "Experimental investigation of in-wheel switched reluctance motor driving system for future electric vehicles," in Proceedings of the $3 \mathrm{rd}$ International Conference on Power Electronics Systems and Applications (PESA '09), pp. 1-6, Hong Kong, May 2009. 
[38] A. Labak and N. C. Kar, "Outer rotor switched reluctance motor design for in-wheel drive of electric bus applications," in Proceedings of the 20th International Conference on Electrical Machines (ICEM '12), pp. 418-423, Marseille, France, September 2012.

[39] S. Ayari, M. Besbes, M. Lecrivain, and M. Gabsi, "Effects of the airgap eccentricity on the SRM vibrations," in Proceedings of the International Conference Electric Machines and Drives, pp. 138140, 1999.

[40] H. Torkaman and E. Afjei, "Magnetostatic field analysis regarding the effects of dynamic eccentricity in switched reluctance motor," Progress in Electromagnetics Research, vol. 8, pp. 163180, 2009.

[41] I. Husain, "Minimization of torque ripple in SRM drives," IEEE Transactions on Industrial Electronics, vol. 49, no. 1, pp. 28-39, 2002.

[42] Y. A. Beromi, Z. Moravej, and S. Darabi, "Torque ripple reduction of switched reluctance motor using PID fuzzy logic controller," in Proceedings of the 7th International Conference and Exposition on Electrical and Power Engineering (EPE '12), pp. 456-459, Iasi, Romania, October 2012.

[43] S. M. Kuo and D. R. Morgan, Active Noise Control Systems, Wiley, New York, NY, USA, 1996.

[44] L. Vicente and E. Masgrau, "Novel FxLMS convergence condition with deterministic reference," IEEE Transactions on Signal Processing, vol. 54, no. 10, pp. 3768-3774, 2006.

[45] D. Zhou and V. DeBrunner, "Efficient adaptive nonlinear filters for nonlinear active noise control," IEEE Transactions on Circuits and Systems I: Regular Papers, vol. 54, no. 3, pp. 669681, 2007.

[46] D. Karnopp, "Active damping in road vehicle suspension systems," Vehicle System Dynamics, vol. 12, no. 6, pp. 291-316, 1983.

[47] C. Ting, T. S. Li, and F. Kung, "Design of fuzzy controller for active suspension system," Mechatronics, vol. 5, no. 4, pp. 365$383,1995$. 

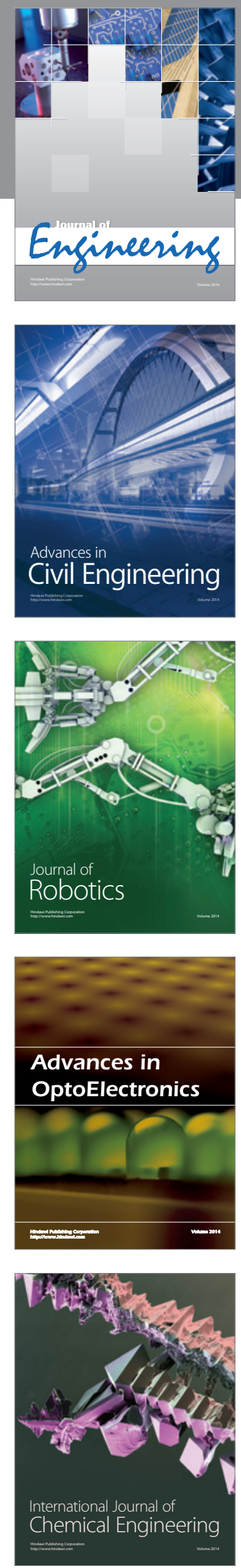

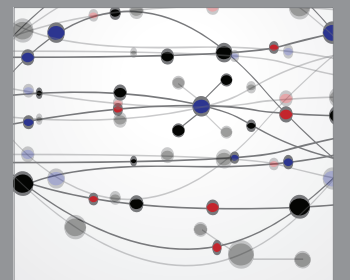

The Scientific World Journal
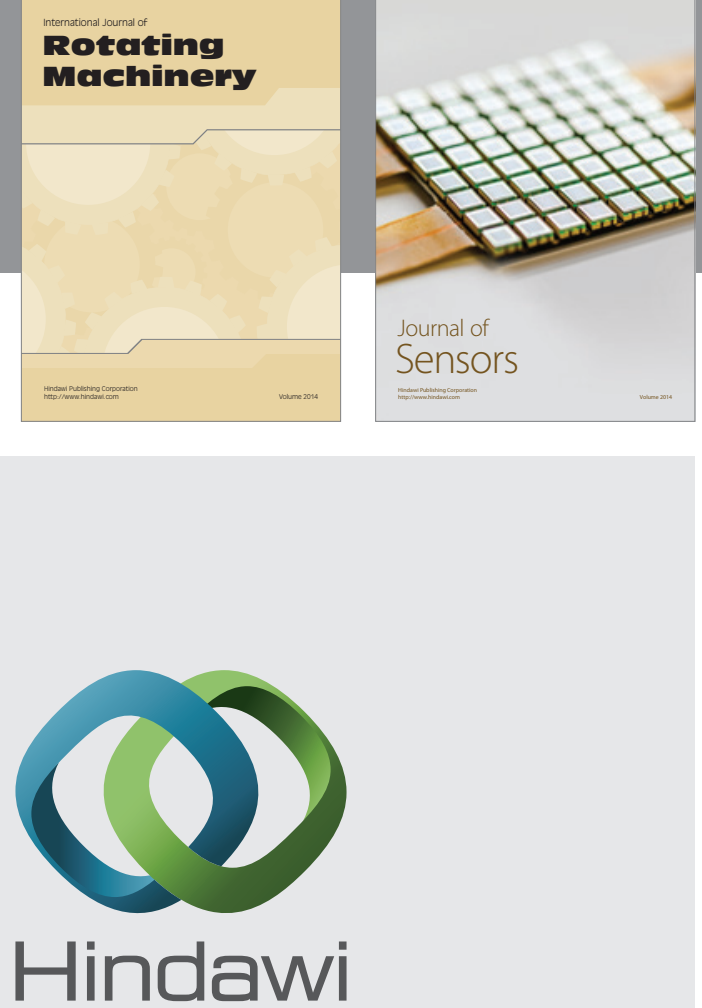

Submit your manuscripts at http://www.hindawi.com
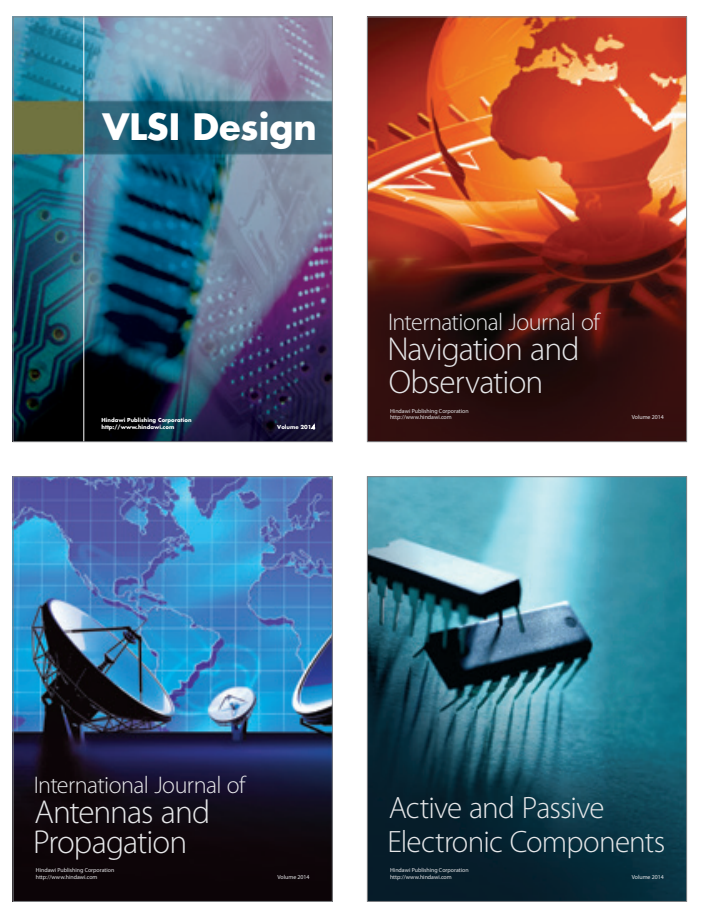
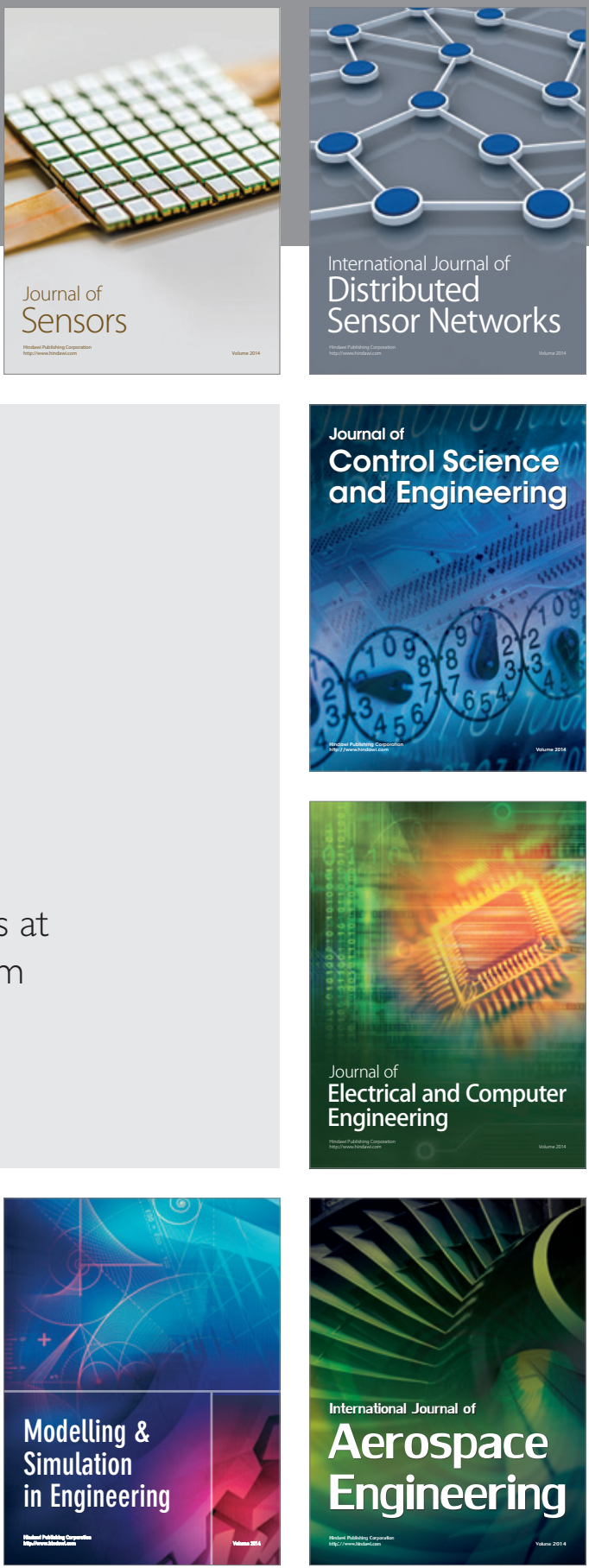

Journal of

Control Science

and Engineering
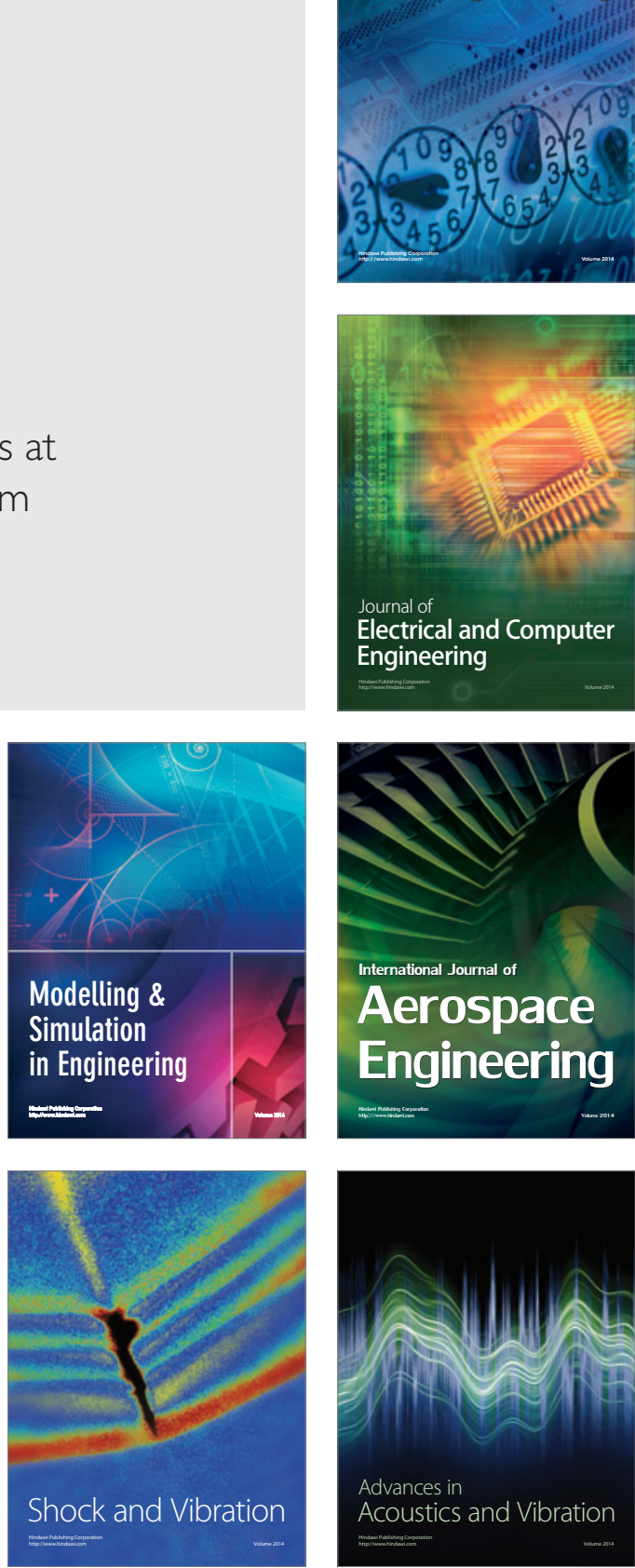